Research Article

\title{
Residual Compressive Strength of High-Strength Concrete Exposed to Elevated Temperatures
}

\author{
Hussein M. Elsanadedy (iD) ${ }^{1,2}$ \\ ${ }^{1}$ Chair of Research and Studies in Strengthening and Rehabilitation of Structures, Dept. of Civil Eng., College of Eng., \\ King Saud University, P.O. Box 800, Riyadh 11421, Saudi Arabia \\ ${ }^{2}$ On Leave from Helwan University, Cairo, Egypt
}

Correspondence should be addressed to Hussein M. Elsanadedy; elsanadedy@yahoo.com

Received 10 March 2019; Accepted 7 May 2019; Published 28 May 2019

Academic Editor: Barbara Liguori

Copyright ( $) 2019$ Hussein M. Elsanadedy. This is an open access article distributed under the Creative Commons Attribution License, which permits unrestricted use, distribution, and reproduction in any medium, provided the original work is properly cited.

\begin{abstract}
High-strength concrete (HSC) has several well-known technical, aesthetic, and economic advantages over normal-strength concrete (NSC), which explains the increasing popularity of the former material in the construction domain. As in the case of NSC, however, high temperature adversely affects HSC mechanical properties even more than in NSC, as indicated by the many studies performed so far on HSC at high temperature (hot properties) or past a thermal cycle at high temperature (residual properties). Since many code provisions concerning concrete properties versus high temperature were developed for ordinary concrete and the available models (in terms of stress-strain relationship) come mostly from the tests on NSC-as the tests on HSC are less numerous-developing predictive relationships for HSC exposed to high temperature is still an open issue, especially with reference to many parameters affecting concrete compressive strength, like temperature as such, heating rate, water-to-binder ratio, and strength in compression, to cite the most relevant parameters. To this purpose, a large database (more than 600 tests) is examined in this paper, which is focused on HSC residual properties and on the variables affecting its residual strength. Available design models from various guidelines, standards, codes, and technical reports are tested against the database, and new regressionbased models and design formulae are proposed for HSC strength in compression, after the exposure to high temperature.
\end{abstract}

\section{Introduction}

High-strength concrete (HSC) is gaining popularity over normal-strength concrete (NSC) in the design of various structural components because of many advantages of such concrete [1]. As per ACI 363R-10 [2], HSC is defined as concrete having compressive strength greater than $41.4 \mathrm{MPa}$ (6000 psi). This criterion is followed in the current study to identify the two concrete types. The advantages of HSC over NSC include better mechanical properties such as improved durability, higher stiffness, and strength. The economic advantages are obtained as a result of reductions in section dimensions of structural members thereby increasing the usable space [3].

High-temperature exposure is known to adversely affect the mechanical properties of concrete [4-15]. There exist three steady-state temperature tests available in the literature to determine the mechanical properties of concrete at elevated temperature, as shown in Figure 1 [16]. In the first type, i.e., the stressed tests, the specimen is preloaded before heating and the preload is maintained during the heating period. The preload may vary from 20 to $40 \%$ of the compressive strength of concrete at ambient temperature. The rate of increase in heat is usually kept constant till the desired temperature is achieved, to guarantee quasi-steady thermal conditions during the heating process. After a rest period at the desired (i.e., nominal) temperature to make the thermal field as uniform as possible, the load is increased until the failure of the specimen in compression (Figure 1(a)). In the second type test (i.e., unstressed test), there is no preload and the specimen is directly heated to the desired temperature usually at a constant rate. In this test also, the peak temperature is sustained for prescribed period for achieving the thermal steady state. Subsequently, the 

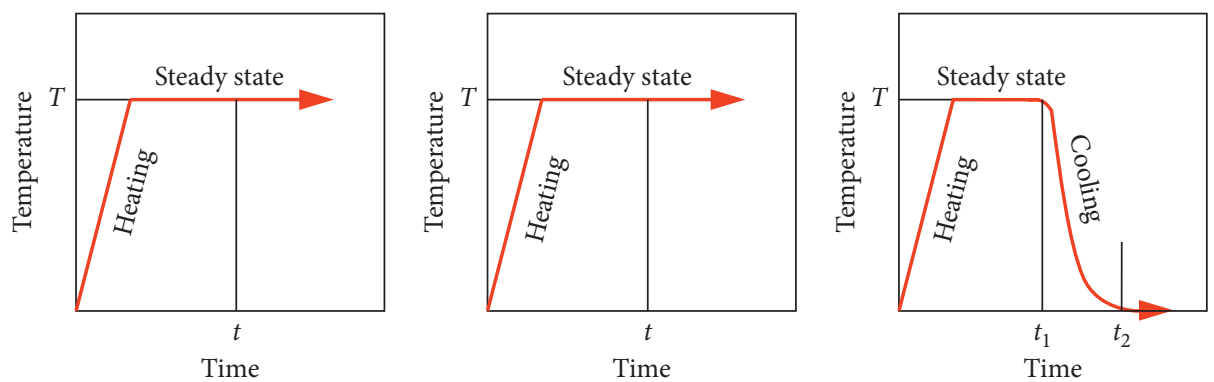

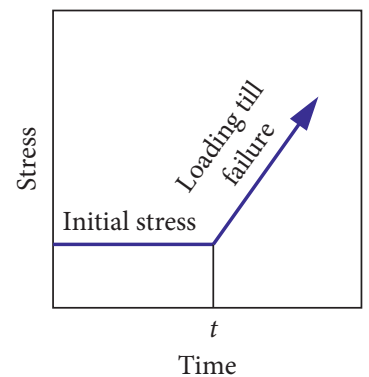

(a)

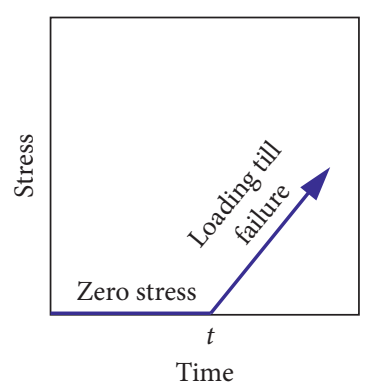

(b)

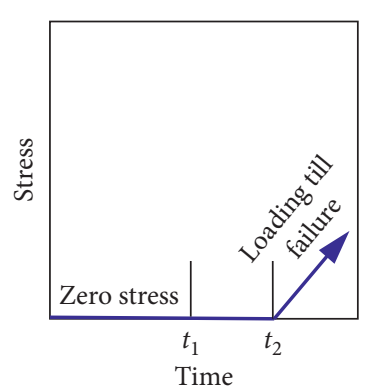

(c)

Figure 1: Schematic of temperature and loading histories for the three test methods [16]. (a) Stressed test. (b) Unstressed test. (c) Residual property.

specimen is loaded up to failure (Figure 1(b)). In the third type of test (i.e., unstressed residual test), no preload is applied during the heating process and the specimen is cooled down to room temperature (possibly under controlled conditions, i.e., at a constant cooling rate) before being loaded in compression until concrete crushing (Figure 1(c)).

Because of research on the impact of high-temperature exposure on concrete properties [17-26], it has been reported that the performance of NSC at elevated temperature is different from HSC at the same temperature. The review of behavior of HSC in fire $[27,28]$ revealed two dominant distinctions between NSC and HSC at high-temperature exposure: (1) at temperatures ranging from $100^{\circ} \mathrm{C}$ to $400^{\circ} \mathrm{C}$, there is a difference in relative strength loss, and (2) at temperatures ranging from $200^{\circ} \mathrm{C}$ to $400^{\circ} \mathrm{C}$, the explosive spalling was noticed in HSC test specimens. The explosive spalling in HSC, one of the major concerns, is mainly due to its denser microstructure causing low permeability. This makes it difficult for the water vapor to escape to the outside environment and consequently increases the pore pressure in cement paste which is mainly responsible for the explosive spalling in HSC. Thus, there is a need for resolving the questions about the performance of HSC exposed to elevated temperature (or fire). Moreover, the available fire-design guidelines-developed typically based on the test data of NSC-cannot be simply extended to HSC.

There are several existing models for assessing the residual compressive strength of concrete after exposure to elevated temperature $[4-6,29-34]$. Nevertheless, these available models were either developed for NSC or derived from inadequate test data on HSC, which was not sufficient to cover all affecting parameters. The goal of this study is to come up with predictive relationships taking care of the major parameters affecting concrete strength at high temperature and the strength loss. It should be noted that deterministic prediction of concrete behavior may be difficult due to its heterogeneous nature that leads to substantial inconsistency in its properties. Theoretical developments are not, therefore, the objective of this research, and the models will be developed on the basis of statistical regression analysis of the available experimental database.

Aslani and Bastami [31] developed predictive models for both NSC and HSC subjected to high temperature. These relationships were obtained for tensile and compressive strengths, modulus of elasticity, and stress-strain (tensile and compressive) behavior of unconfined concrete at elevated temperatures. Nevertheless, the database employed to generate the models for HSC is inadequate (less than 100 test specimens were utilized), and it is also limited to siliceousaggregate concrete. A recommendation was given to add more test results to the database in order to cover wider range of affecting parameters.

As a result of the research carried out since the 1950s on HSC exposed to high temperature, there exist extensive database on the performance of HSC under hightemperature exposure. An inclusive assessment of these data is missing, however. The residual compressive strength models developed in this research intend to bridge this gap through employing a comprehensive database for increasing the statistical sturdiness. A sufficiently large experimental database (617 data points)_obtained from the accessible literature pertaining to the tests on HSC exposed to elevated temperature environments-was thoroughly examined to assess the impact of various parameters on the residual compressive strength of HSC with strength exceeding $100 \mathrm{MPa}$. The collected database was employed to assess the applicability of the available models from guidelines, 
standards, codes, and researchers. New regression-based models were also developed for the prediction of residual compressive strength of HSC after being exposed to elevated temperature. The test results were subsequently compared with the predicted results of the regression-based models. Finally, new residual concrete strength design equations for HSC were developed in order to be utilized in fire design of concrete structures.

\section{Existing Models in Codes and Research Publications}

Table 1 shows the models for the assessment of the residual concrete strength postexposure to elevated temperature that are available in codes and standards such as Eurocode 2: EN 1992-1-2 [4] and ACI 216.1-07 [5] in addition to ASCE Manual of practice [6]. These are one-variable models, which depend only on the elevated temperature, $T$. The effect of all other variables is ignored except the model of ACI 216.1-07 [5], which employs different curves for siliceous and calcareous aggregates. Table 1 also lists the models developed by researchers [29-34] for predicting residual concrete strength. The following distinguishing features are noted on these models:

(i) Some of the collected data points demonstrate enhancement in concrete strength when exposed to moderately lower temperatures; however, this trend is not shown in any of the available models. A reduction in concrete strength for temperature higher than $20^{\circ} \mathrm{C}$ is demonstrated in most of the existing models [33]. Yet, the model of the ASCE Manual of practice [6] reveals no change of compressive strength for temperatures up to $450^{\circ} \mathrm{C}$.

(ii) The model of Eurocode 2 [4] is not valid for HSC with strength exceeding $90 \mathrm{MPa}$. Although the effect of type of aggregate (calcareous or siliceous) is considered for concrete with $f_{\mathrm{c}, \mathrm{r}}^{\prime}<55.0 \mathrm{MPa}$, it is not taken into account for HSC having $f_{\mathrm{c}, \mathrm{r}}^{\prime} \geq 55.0 \mathrm{MPa}$.

(iii) The curves given in ACI 216.1-07 [5] clarify that the unstressed residual concrete strength is the lowest amongst the three test procedures presented in Figure 1. It should be noted that the peak temperature reached in these curves is $871^{\circ} \mathrm{C}$ (i.e., $1600^{\circ} \mathrm{F}$ ). The trend of curves indicates better high temperature resistance (unstressed residual) for siliceous-aggregate concrete in comparison with calcareous-aggregate concrete. The effect of type of aggregate on the residual strength of HSC is unidentified as these curves are generated only for NSC; however, there is no limit in the code on the concrete strength for the use of these curves. Moreover, no other code or researchers' models consider difference between the aggregate types (calcareous or siliceous) for HSC except Aslani and Bastami [31]. Although ASCE Manual [6] also uses the same curves as given in ACI 216.1-07 [5], a simple linear model is suggested for assessment of the residual concrete strength regardless of the aggregate type. Even though the two codes do not differentiate between NSC and HSC, it is apparent that these models $[5,6]$ are only intended for NSC.

(iv) The models given by some researchers [29, 32, 33] are piecewise linear for dissimilar ranges of $T$. Yet, Choe et al. [32] considered 7 ranges of $T$ thereby providing five different formulae for assessing the residual concrete strength.

(v) The models of both Nielsen et al. [30] and Hertz [34] are the only ones that are applicable for whole temperature range. The model developed by Nielsen et al. [30] is a single quadratic equation in $T$. However, the equation proposed by Hertz [34] has a numerator of one and a 64-degree polynomial of $T$ as the denominator.

(vi) Aslani and Bastami [31] proposed several formulae for various ranges of $T$ and $f_{\mathrm{c}}^{\prime}$. The developed formulae are linear and cubic in $T$.

\section{Experimental Data Set}

A significantly large data set of available experimental results on the residual compressive strength of HSC after being exposed to high temperature was compiled. The experimental data were considered sufficient for deep investigation of different affecting parameters. These data were compiled from published sources including conference proceedings, journal papers, student theses, and technical reports. The data taken from the literature were for those studies wherein most of the geometric dimensions of specimens and material properties were available. The database contains results of 617 specimens (including those at room temperature), out of which 485 specimens were exposed to high temperature. Summary of the collected experimental database is given in Table 2. The data were obtained from 54 studies reporting experiments performed during the period from 1965 to 2017 [7, 10, 11, 24, 35-84]. The following criteria were used for achieving consistency in the data set:

(i) Data are only for the HSC specimens with $f_{c, r}^{\prime}>$ $41.4 \mathrm{MPa}$ (following the limits of ACI 363R-10 [2]).

(ii) Data are for unreinforced concrete specimens such as cylinders and cubes.

(iii) Concrete mix contains no fibers.

(iv) The concrete mix contains mineral additives (such as fly ash and silica fume) not more than $15 \%$ of the weight of cement.

(v) Ordinary Portland cement is utilized in the concrete mix.

(vi) The specimens are subjected to heating regimes at rates between 0.5 and $20^{\circ} \mathrm{C} / \mathrm{min}$, and the elevated temperature is sustained to guarantee quasi-steady thermal state. Then, natural air cooling is used to bring the temperature of specimens down to ambient temperature. Next, the specimens are 
TABLE 1: Models for residual compressive strength of concrete after high-temperature exposure.

\begin{tabular}{|c|c|}
\hline Code/researcher & Compressive strength after high temperature exposure $\left(f_{c, T}^{\prime}\right)$ \\
\hline Eurocode 2: EN 1992-1-2 [4] & $\begin{array}{l}\text { (i) If } 41.4<f_{c, r}^{\prime}<55.0 \mathrm{MPa} \text {, use Table } 3.1 \text { of the code. } \\
\text { (ii) If } f_{c, r}^{\prime} \geq 55.0 \mathrm{MPa} \text {, use Table } 6.1 \mathrm{~N} \text { of the code. }\end{array}$ \\
\hline ACI 216.1-07 [5] & $\begin{array}{l}\text { (i) For siliceous aggregate, use curve from Figure } 2.12(\mathrm{a}) \text { of the code. } \\
\begin{array}{ll}\text { (ii) For calcareous (carbonate) aggregate, use curve from Figure } 2.12(\mathrm{~b}) \text { of the code. } \\
\qquad f_{\mathrm{c}, \mathrm{r}}^{\prime}, \quad \text { for } 20^{\circ} \mathrm{C} \leq T \leq 450^{\circ} \mathrm{C},\end{array}\end{array}$ \\
\hline ASCE Manual [6] & $f_{\mathrm{c}, \mathrm{T}}^{\prime}= \begin{cases}\left.f_{\mathrm{c}, \mathrm{r}} \mathrm{c}, \mathrm{r}, 011-2.353((T-20) / 1000)\right], & \text { for } 450^{\circ} \mathrm{C} \leq \mathrm{T} \leq 874^{\circ} \mathrm{C} \\
0, & \text { for } T>874^{\circ} \mathrm{C}\end{cases}$ \\
\hline Kodur et al. [29] & $f_{\mathrm{c}, \mathrm{T}}^{\prime}= \begin{cases}f_{\mathrm{c}, \mathrm{r}}^{\prime}[1.0-0.003125(T-20)], & \text { for } T<100^{\circ} \mathrm{C} \\
0.75 f_{c, \mathrm{r}}^{\prime}, & \text { for } 100^{\circ} \mathrm{C} \leq T \leq 400^{\circ} \mathrm{C} \\
f_{\mathrm{c}, \mathrm{r}}^{\prime}(1.33-0.00145 T), & \text { for } T>400^{\circ} \mathrm{C}\end{cases}$ \\
\hline Nielsen et al. [30] & $f_{\mathrm{c}, \mathrm{T}}^{\prime}=f_{\mathrm{c}, \mathrm{r}}^{\prime}\left(1-0.016 \theta^{2}\right), \quad \theta=\frac{T-20}{100}, 0 \leq \theta \leq 7.9$ \\
\hline Aslani and Bastami [31] & $\begin{array}{l}\text { For siliceous aggregate, if } 41.4<f_{\mathrm{c}, \mathrm{r}}^{\prime}<55.2 \mathrm{MPa}, \\
f_{\mathrm{c}, \mathrm{T}}^{\prime}= \begin{cases}f_{\mathrm{c}, \mathrm{r}}^{\prime}(1.012-0.0005 T), & \text { for } 20^{\circ} \mathrm{C} \leq T \leq 100^{\circ} \mathrm{C}, \\
f_{\mathrm{c}, \mathrm{r}}\left(0.985+0.0002 T-2.235 \times 10^{-6} T^{2}+8 \times 10^{-10} T^{3}\right), & \text { for } 100^{\circ} \mathrm{C}<T \leq 800^{\circ} \mathrm{C}, \\
f_{\mathrm{c}, \mathrm{r}}(0.44-0.0004 T), & \text { for } 800^{\circ} \mathrm{C} \leq T \leq 1000^{\circ} \mathrm{C},\end{cases} \\
\text { If } 55.2 \leq f_{\mathrm{c}, \mathrm{r}}^{\prime} \leq 80 \mathrm{MPa}, \\
f_{\mathrm{c}, \mathrm{T}}^{\prime}= \begin{cases}f_{\mathrm{c}, \mathrm{r}}^{\prime}(1.01-0.00068 T), & \text { for } T>1000^{\circ} \mathrm{C} . \\
f_{\mathrm{c}, \mathrm{r}}^{\prime}\left(0.935+0.00026 T-2.13 \times 10^{-6} T^{2}+8 \times 10^{-10} T^{3}\right), & \text { for } 20^{\circ} \mathrm{C} \leq T \leq 200^{\circ} \mathrm{C}, \\
f_{c, \mathrm{r}}^{\prime}\left(0.90+0.0002 T-2.13 \times 10^{-6} T^{2}+8 \times 10^{-10} T^{3}\right), & \text { for } 400^{\circ} \mathrm{C}<T \leq 400^{\circ} \mathrm{C}, \\
f_{\mathrm{c}, \mathrm{r}}^{\prime}(0.44-0.0004 T), & \text { for } 800^{\circ} \mathrm{C}<T \leq 1000^{\circ} \mathrm{C}, \\
0, & \text { for } T>1000^{\circ} \mathrm{C} .\end{cases} \end{array}$ \\
\hline & $\begin{array}{l}\text { If } f_{\mathrm{c}, \mathrm{r}}^{\prime}>80 \mathrm{MPa} \\
f_{\mathrm{c}, \mathrm{T}}^{\prime}= \begin{cases}f_{\mathrm{c}, \mathrm{r}}^{\prime}(0.8-0.0005 T) \leq 1.0, & \text { for } 20^{\circ} \mathrm{C} \leq T \leq 500^{\circ} \mathrm{C}, \\
f_{\mathrm{c}, \mathrm{r}}^{\prime}\left(0.96-0.0008 T-5.17 \times 10^{-7} T^{2}+4 \times 10^{-10} T^{3}\right), & \text { for } 500^{\circ} \mathrm{C}<T \leq 800^{\circ} \mathrm{C} \\
f_{\mathrm{c}, \mathrm{r}}^{\prime}(0.44-0.0004 T), & \text { for } 800^{\circ} \mathrm{C}<T \leq 1000^{\circ} \mathrm{C} \\
0, & \text { for } T>1000^{\circ} \mathrm{C}\end{cases} \end{array}$ \\
\hline & $\begin{array}{l}\text { For calcareous aggregate, } \\
f_{\mathrm{c}, \mathrm{T}}^{\prime}= \begin{cases}f_{\mathrm{c}, \mathrm{r}}^{\prime}(1.01-0.0006 T) \leq 1.0, & \text { for } 20^{\circ} \mathrm{C} \leq \mathrm{T} \leq 200^{\circ} \mathrm{C} \\
f_{\mathrm{c}, \mathrm{r}}\left(1.0565+0.0017 T+5 \times 10^{-6} T^{2}-5 \times 10^{-9} T^{3}\right), & \text { for } 200^{\circ} \mathrm{C}<\mathrm{T} \leq 900^{\circ} \mathrm{C} \\
0, & \text { for } T>900^{\circ} \mathrm{C}\end{cases} \end{array}$ \\
\hline Choe et al. [32] & $f_{\mathrm{c}, \mathrm{T}}^{\prime}= \begin{cases}f_{\mathrm{c}, \mathrm{r}}^{\prime}, & \text { for } T \leq 20^{\circ} \mathrm{C} \\
f_{\mathrm{c}, \mathrm{r}}(1.0375-0.0019 T), & \text { for } 20^{\circ} \mathrm{C}<T \leq 100^{\circ} \mathrm{C} \\
0.85 f_{\mathrm{c}, \mathrm{r}}^{\prime}, & \text { for } 100^{\circ} \mathrm{C}<T \leq 200^{\circ} \mathrm{C} \\
f_{\mathrm{c}, \mathrm{r}}^{\prime}(1.1-0.0013 T), & \text { for } 200^{\circ} \mathrm{C}<T \leq 700^{\circ} \mathrm{C} \\
f_{\mathrm{c}, \mathrm{r}}^{\prime}(0.62-0.0006 T), & \text { for } 700^{\circ} \mathrm{C}<T \leq 900^{\circ} \mathrm{C} \\
f_{\mathrm{c}, \mathrm{r}}(0.32-0.0003 T), & \text { for } 900^{\circ} \mathrm{C}<T \leq 1200^{\circ} \mathrm{C} \\
0, & \text { for } T>1200^{\circ} \mathrm{C}\end{cases}$ \\
\hline Phan and Carino [33] & $f_{\mathrm{c}, \mathrm{T}}^{\prime}= \begin{cases}f_{\mathrm{c}, \mathrm{r}}^{\prime}, & \text { for } T \leq 50^{\circ} \mathrm{C} \\
f_{\mathrm{c}, \mathrm{r}}^{\prime}(1.28-0.0056 T), & \text { for } 50^{\circ} \mathrm{C}<T \leq 100^{\circ} \mathrm{C} \\
0.72 f_{\mathrm{c}, \mathrm{r}}^{\prime}, & \text { for } 100^{\circ} \mathrm{C}<T \leq 350^{\circ} \mathrm{C} \\
f_{\mathrm{c}, \mathrm{r}}^{\prime}(1.31-0.00168 T), & \text { for } 350^{\circ} \mathrm{C}<T \leq 778^{\circ} \mathrm{C} \\
0, & \text { for } T>778^{\circ} \mathrm{C}\end{cases}$ \\
\hline Hertz [34] & $f_{\mathrm{c}, \mathrm{T}}^{\prime}=f_{\mathrm{c}, \mathrm{r}}^{\prime}\left(\frac{1}{1+(T / 10000)+(T / 780)^{2}+(T / 490)^{8}+(T / 100000)^{64}}\right)$. \\
\hline
\end{tabular}

concentrically loaded up to failure to assess their residual strength.

(vii) Enough details for different geometric and material characteristics are available for achieving better confidence in the derivation of results.

It should be noted that the database shown in Table 2 is for different sizes of the cylinder and cube specimens. The formulae proposed by $\mathrm{Yi}$ et al. [85] were employed to convert the compressive strength measured for cubes and cylinders of different dimensions to that of the standard $150 \times 300 \mathrm{~mm}$ cylinder as follows:

$$
\begin{aligned}
& f_{\mathrm{c}}^{\prime}=\frac{f_{\mathrm{cy}}(h, d)}{(0.4 / \sqrt{1+(h-d / 50)}+0.8)}, \\
& f_{\mathrm{c}}^{\prime}=\frac{f_{\mathrm{cu}}(d)}{((1.17 / \sqrt{1+(d / 26)})+0.62)},
\end{aligned}
$$


TABLE 2: Summary of the experimental database used in this study ${ }^{\uparrow}$.

\begin{tabular}{|c|c|c|c|c|c|c|c|c|}
\hline Reference & $\begin{array}{c}\text { Type of } \\
\text { coarse } \\
\text { aggregate }\end{array}$ & $\begin{array}{c}\text { Aggregate/ } \\
\text { binder ratio, } \\
a / b\end{array}$ & $\begin{array}{l}\text { Water/ } \\
\text { binder } \\
\text { ratio, } w / b\end{array}$ & $\begin{array}{l}\text { Heating } \\
\text { rate, } H_{r} \\
\left({ }^{\circ} \mathrm{C} / \mathrm{min}\right)\end{array}$ & $\begin{array}{c}\text { Room } \\
\text { temperature, } \\
T_{\mathrm{o}}\left({ }^{\circ} \mathrm{C}\right)\end{array}$ & $\begin{array}{c}\text { Elevated } \\
\text { temperature, } \\
T\left({ }^{\circ} \mathrm{C}\right)\end{array}$ & $\begin{array}{c}f_{c, r}^{\prime} \\
(\mathrm{MPa})\end{array}$ & $\begin{array}{c}\text { No. of } \\
\text { specimens* }\end{array}$ \\
\hline Liu [35] & Siliceous & 2.53 & 0.35 & 10 & 20 & $\begin{array}{l}400,500,600 \\
700,800\end{array}$ & 73.4 & $6(5)$ \\
\hline Caple [36] & Calcareous & 1.58 & 0.16 & 2.5 & 20 & $\begin{array}{c}200,400,500, \\
600\end{array}$ & 51.0 & $15(14)$ \\
\hline Peng [37] & Siliceous & $\begin{array}{c}1.98,2.16 \\
2.38,2.49 \\
2.6,3.04\end{array}$ & $\begin{array}{c}0.21,0.26 \\
0.32,0.35 \\
0.38,0.5\end{array}$ & $1,2.5,5$ & 25 & $\begin{array}{c}200,300,400 \\
500,600,700 \\
800,1000 \\
1200\end{array}$ & $\begin{array}{c}56.8,82.4, \\
94.6,100.5, \\
111.6\end{array}$ & $59(53)$ \\
\hline $\mathrm{Xu}$ et al. [38] & Siliceous & $2.17,2.76$ & $0.3,0.5$ & 1 & 25 & $\begin{array}{c}250,450,650, \\
800\end{array}$ & $46.1,103.5$ & $10(8)$ \\
\hline Arioz [39] & Calcareous & 1.32 & 0.32 & 1 & 20 & $200,400,600$ & 71.6 & $4(3)$ \\
\hline Martins et al. [40] & Calcareous & 2.84 & 0.52 & 2.5 & 20 & $200,400,600$ & 61.8 & $4(3)$ \\
\hline Yaqub and Bailey [41] & Siliceous & NA & 0.55 & 2.5 & 20 & $\begin{array}{c}200,300,450, \\
500,\end{array}$ & 49.5 & $8(6)$ \\
\hline Biolzi et al. [42] & Siliceous & NA & 0.22 & 1 & 20 & $250,500,750$ & 93.3 & $4(3)$ \\
\hline Türkmen et al. [11] & NA & 3.25 & 0.35 & 15 & 23 & $\begin{array}{c}100,200,300 \\
400,500\end{array}$ & 63.3 & $6(5)$ \\
\hline Al-Jabri et al. [43] & $\begin{array}{l}\text { Siliceous/ } \\
\text { calcareous }\end{array}$ & 2.29 & 0.50 & 2 & 25 & $\begin{array}{c}200,400,600 \\
800,1000\end{array}$ & 42.7 & $6(5)$ \\
\hline Kerr [44] & Calcareous & $\begin{array}{l}0.84,1.28 \\
2.19,2.27 \\
\quad 3.91\end{array}$ & $\begin{array}{l}0.22,0.3 \\
0.56\end{array}$ & 5.0 & 25 & $\begin{array}{c}105,200,300 \\
600\end{array}$ & $\begin{array}{c}42.2,47.8 \\
72.3,76.6,79 \\
80,83.5,86.8\end{array}$ & $25(17)$ \\
\hline Bastami et al. [45] & Siliceous & $\begin{array}{c}1.64,1.68 \\
1.77,1.85 \\
1.87,1.88 \\
1.93,1.97 \\
2.0,2.14,2.35\end{array}$ & $\begin{array}{c}0.21,0.22, \\
0.23,0.25 \\
0.26,0.27 \\
0.28,0.29 \\
0.3\end{array}$ & 20 & 25 & 800 & $\begin{array}{c}64.5,65.8,66 \\
76.2,76.7 \\
77.5,78.5 \\
80.3,81.4 \\
82.3,85.7 \\
90.1,93.6\end{array}$ & $28(14)$ \\
\hline Bastami et al. [46] & Siliceous & 2.09 & 0.25 & 20 & 20 & $400,600,800$ & $\begin{array}{l}82.5,84.1 \\
85.1,85.2 \\
85.8,87.4 \\
87.6,90.6\end{array}$ & $32(24)$ \\
\hline Sideris and Manita [47] & Siliceous & 1.75 & 0.44 & 5 & 20 & 300,600 & 45.4 & $3(2)$ \\
\hline Tolentino et al. [48] & Siliceous & $2.57,2.60$ & $0.28,0.42$ & 0.83 & 25 & 600 & $50.4,62.1$ & $4(2)$ \\
\hline Felicetti et al. [49] & Siliceous & 2.77 & 0.29 & 1 & 20 & $\begin{array}{c}105,250,400 \\
600\end{array}$ & 98.1 & $5(4)$ \\
\hline Elsanadedy et al. [7] & Calcareous & 2.63 & 0.43 & 10 & 26 & $\begin{array}{l}100,200,300 \\
400,500,800\end{array}$ & 43.4 & $7(6)$ \\
\hline Hager et al. [50] & $\begin{array}{l}\text { Siliceous, } \\
\text { calcareous }\end{array}$ & $\begin{array}{l}2.42,2.52 \\
2.56,2.82\end{array}$ & 0.30 & 0.5 & 20 & $\begin{array}{c}200,400,600 \\
800,1000\end{array}$ & $\begin{array}{l}71.2,71.6 \\
73.2,80.1\end{array}$ & $23(19)$ \\
\hline Gupta et al. [10] & Siliceous & 3.09 & 0.45 & 5 & 27 & $\begin{array}{c}150,300,450 \\
600,750\end{array}$ & $43.9,44$ & $18(15)$ \\
\hline Lee et al. [51] & Siliceous & 2.78 & 0.45 & 13.33 & 20 & $\begin{array}{l}100,200,300 \\
400,500,600\end{array}$ & 57.4 & $7(6)$ \\
\hline $\begin{array}{l}\text { Ahmad and } \\
\text { Abdulkareem [52] }\end{array}$ & Siliceous & 3.07 & 0.54 & 5 & 20 & $200,400,600$ & $44.5,48.4$ & $8(6)$ \\
\hline Chowdhury [53] & NA & $1.26,1.94$ & $0.23,0.29$ & 8.33 & 22 & $100,200,400$ & $72.6,91.4$ & $16(14)$ \\
\hline Rao and Kumar [54] & NA & NA & 0.32 & NA & 25 & $\begin{array}{l}200,400,800 \\
105,200,300,\end{array}$ & 55.6 & $4(3)$ \\
\hline Lau [55] & Siliceous & $3.07,3.16$ & $0.32,0.56$ & $3,4,5$ & 25 & $\begin{array}{c}400,600,800 \\
1000,1100 \\
1200\end{array}$ & $46.0,86.0$ & $20(18)$ \\
\hline Purkiss [56] & Siliceous & NA & 0.45 & 2 & 20 & $\begin{array}{l}300,400,500 \\
600,700,800\end{array}$ & $55.1,63.9$ & $8(6)$ \\
\hline Netinger et al. [57] & Calcareous & 4.59 & 0.43 & 1 & 20 & 400,800 & 70.4 & $3(2)$ \\
\hline Phan et al. [24] & Calcareous & $1.28,2.27$ & $\begin{array}{c}0.2,0.3 \\
0.57\end{array}$ & 5 & 25 & $\begin{array}{c}100,200,300 \\
450\end{array}$ & $\begin{array}{l}49.1,73.1 \\
85.3,89.7\end{array}$ & $19(15)$ \\
\hline Toumi et al. [58] & Calcareous & 2.64 & 0.37 & 10 & 20 & $300,500,700$ & 61.3 & $11(10)$ \\
\hline
\end{tabular}


TABLE 2: Continued.

\begin{tabular}{|c|c|c|c|c|c|c|c|c|}
\hline Reference & $\begin{array}{c}\text { Type of } \\
\text { coarse } \\
\text { aggregate }\end{array}$ & $\begin{array}{c}\text { Aggregate/ } \\
\text { binder ratio, } \\
a / b\end{array}$ & $\begin{array}{l}\text { Water/ } \\
\text { binder } \\
\text { ratio, } w / b\end{array}$ & $\begin{array}{l}\text { Heating } \\
\text { rate, } H_{r} \\
\left({ }^{\circ} \mathrm{C} / \mathrm{min}\right)\end{array}$ & $\begin{array}{c}\text { Room } \\
\text { temperature, } \\
T_{\mathrm{o}}\left({ }^{\circ} \mathrm{C}\right)\end{array}$ & $\begin{array}{c}\text { Elevated } \\
\text { temperature, } \\
T\left({ }^{\circ} \mathrm{C}\right)\end{array}$ & $\begin{array}{c}f_{c, r}^{\prime} \\
(\mathrm{MPa})\end{array}$ & $\begin{array}{c}\text { No. of } \\
\text { specimens* }\end{array}$ \\
\hline Uysal and Tanyildizi [59] & Calcareous & $\begin{array}{l}1.39,1.40 \\
1.41\end{array}$ & 0.33 & 1 & 20 & $\begin{array}{l}200,400 \\
600,800\end{array}$ & $\begin{array}{c}62.2,63.7 \\
64.4,65.9 \\
\quad 66.2\end{array}$ & $25(20)$ \\
\hline Hachemi et al. [60] & Calcareous & $1.7,2.18$ & $0.27,0.42$ & 3 & 20 & $\begin{array}{l}150,250,400 \\
\quad 600,900\end{array}$ & $42.9,66.7$ & $11(9)$ \\
\hline Noumowe and Galle [61] & Siliceous & $2.29,3.43$ & $0.3,0.43$ & 1 & 20 & 200 & $48.7,70.3$ & $4(2)$ \\
\hline Chan et al. [62] & Siliceous & $2.14,2.38$ & $0.28,0.35$ & $3,4,5$ & 20 & $\begin{array}{c}400,600,800 \\
1000,1200\end{array}$ & $72.9,102.5$ & $12(10)$ \\
\hline $\begin{array}{l}\text { Demirel and } \\
\text { Kelestemur [63] }\end{array}$ & Siliceous & 1.40 & 0.50 & 2.5 & 20 & $400,600,800$ & 43.2 & $4(3)$ \\
\hline $\begin{array}{l}\text { Anagnostopoulos } \\
\text { et al. [64] }\end{array}$ & Siliceous & 2.55 & 0.50 & 10 & 20 & 300,600 & 47.0 & $3(2)$ \\
\hline Arioz [65] & $\begin{array}{l}\text { Siliceous, } \\
\text { calcareous }\end{array}$ & $1.43,1.64$ & $0.4,0.5$ & 20 & 22 & $\begin{array}{c}200,300,400 \\
500,600,700 \\
750,900\end{array}$ & 42.3 & $14(12)$ \\
\hline $\begin{array}{l}\text { Behnood and } \\
\text { Ghandehari [66] }\end{array}$ & Calcareous & $\begin{array}{l}2.34,2.38 \\
2.40\end{array}$ & $\begin{array}{l}0.3,0.35 \\
0.4\end{array}$ & 3 & 20 & $\begin{array}{l}100,200 \\
300,600\end{array}$ & $\begin{array}{l}60.1,66.3 \\
71.9,81.9\end{array}$ & $20(16)$ \\
\hline Bin Johari [67] & NA & 2.68 & 0.29 & 3.33 & 20 & 200 & 55.2 & $2(1)$ \\
\hline Cülfik and Özturan [68] & Calcareous & $\begin{array}{l}1.96,2.16 \\
2.86\end{array}$ & $\begin{array}{l}0.27,0.3 \\
0.55\end{array}$ & 1 & 20 & $\begin{array}{l}50,100,150 \\
200,250\end{array}$ & $\begin{array}{l}43.2,78.2 \\
\quad 82.5\end{array}$ & $18(15)$ \\
\hline Esen [69] & NA & 2.33 & 0.40 & 4 & 20 & $\begin{array}{c}100,200,300 \\
400,500,600 \\
700,800\end{array}$ & 44.8 & $9(8)$ \\
\hline $\begin{array}{l}\text { Campbell-Allen et al. } \\
\text { [70] }\end{array}$ & Siliceous & NA & 0.44 & 0.83 & 20 & $200,250,300$ & $\begin{array}{l}53.3,55.5 \\
59.4,67.1\end{array}$ & $8(4)$ \\
\hline Hertz [71] & Siliceous & 1.80 & 0.13 & 1 & 20 & $\begin{array}{l}150,350 \\
450,650\end{array}$ & 140.6 & $5(4)$ \\
\hline Khan and Abbas [72] & NA & $2.79,3.41$ & $0.32,0.45$ & 8 & 22 & $\begin{array}{c}100,200,300 \\
400,500 \\
600,700\end{array}$ & $43.4,61.6$ & $13(11)$ \\
\hline $\begin{array}{l}\text { Khandaker and Hossain } \\
\text { [73] }\end{array}$ & Calcareous & 2.03 & 0.30 & 2.5 & 25 & $\begin{array}{l}200,400 \\
600,800\end{array}$ & $\begin{array}{l}60.9,69.2 \\
73.5,74.9\end{array}$ & $20(16)$ \\
\hline Noumowe $[74]$ & Siliceous & 2.57 & 0.34 & 0.5 & 20 & 200 & 61.3 & $2(1)$ \\
\hline Noumowé et al. [75] & Calcareous & 2.58 & 0.42 & 0.5 & 20 & 400 & 75.4 & $2(1)$ \\
\hline Poon et al. [76] & Siliceous & 2.15 & 0.29 & 2.5 & 20 & 600,800 & $67.0,80.3$ & $6(4)$ \\
\hline Savva et al. [77] & $\begin{array}{l}\text { Siliceous, } \\
\text { calcareous }\end{array}$ & $3.47,3.65$ & 0.60 & 2.5 & 20 & $\begin{array}{l}100,300 \\
600,750\end{array}$ & $\begin{array}{l}42.8,45.7 \\
48.2,49.8 \\
51.1\end{array}$ & $24(19)$ \\
\hline $\begin{array}{l}\text { Shaikh and } \\
\text { Vimonsatit [78] }\end{array}$ & Siliceous & 2.20 & 0.45 & 8 & 20 & $\begin{array}{l}200,400 \\
600,800\end{array}$ & $45.8,52.3$ & $10(8)$ \\
\hline Xiao and Falkner [79] & Calcareous & 1.92 & 0.25 & 10 & 20 & $\begin{array}{c}100,200,300 \\
400,500 \\
600,700\end{array}$ & 94.6 & $8(7)$ \\
\hline Zega and Di Maio [80] & Siliceous & $2.28,2.44$ & 0.40 & 10 & 20 & 500 & 44,45 & $4(2)$ \\
\hline Geng et al. $[81]$ & Calcareous & 2.92 & 0.41 & 5 & 25 & 200 & 41.8 & $4(2)$ \\
\hline Morita et al. [82] & $\begin{array}{l}\text { NA } \\
\text { Siliceous, }\end{array}$ & NA & NA & 1 & 20 & $200,350,500$ & 41.5 & $4(3)$ \\
\hline Xing et al. [83] & $\begin{array}{l}\text { calcareous, } \\
\text { silico- } \\
\text { calcareous }\end{array}$ & $\begin{array}{l}0.82,0.92 \\
1.97\end{array}$ & 0.30 & 1 & 20 & $300,600,750$ & $\begin{array}{l}71.1,74.5 \\
79.3\end{array}$ & $12(9)$ \\
\hline Shang and Yi [84] & NA & $1.94,2.06$ & $0.31,0.35$ & 10 & 20 & $\begin{array}{l}200,300 \\
400,500\end{array}$ & $47.9,59.2$ & $10(8)$ \\
\hline \multicolumn{8}{|c|}{ Total no. of specimens $=$} & $617(485)$ \\
\hline
\end{tabular}

${ }^{\top} \mathrm{NA}=$ not available. ${ }^{*}$ Values outside brackets are the total number of test specimens including those at room temperature, whereas values within brackets are the number of specimens exposed to high temperature. 
where $f_{c}^{\prime}$ is the compressive strength of the standard $150 \times 300 \mathrm{~mm}$ concrete cylinder, $f_{\mathrm{cy}}(h, d)$ is the compressive strength of the general cylinder of diameter $d$ (in $\mathrm{mm}$ ) and height $h(\mathrm{~mm})$, and $f_{\mathrm{cu}}(d)$ is the compressive strength of the general cube with size $d(\mathrm{~mm})$.

Table 3 provides the statistics of the data employed in the analysis. The statistics include data range (maximum and minimum values), mean value, standard deviation (SD), coefficient of variation (CV), skewness, and kurtosis. In order to check unevenness in the distribution of the data, the skewness was estimated. For highly skewed data, skewness is greater than 1 . For determination of the shape of data distribution, the kurtosis of the data, listed in Table 3, was also estimated. The kurtosis of data should be 3 in order for the data to conform with the normal distribution curve. Form Table 3, it is clear that data are spread over a wide range due to the large values of coefficient of variation for all independent variables (varying from $28.2 \%$ to $99.4 \%$ ). The aggregate-to-binder ratio varies from 0.82 to 4.59 thus covering a wide range. The same was also observed for the water-to-binder ratio which varies from 0.13 to 0.6 due to concrete mixes that were designed with or without superplasticizers. It is explicable from Table 3 that the peak heating rate of $20^{\circ} \mathrm{C} / \mathrm{min}$ is less than that reached in standard fire tests [86-88]. Yet, the maximum temperature reached in many experiments is $1200^{\circ} \mathrm{C}$ that agrees with the peak fire temperature. It should be noted from Table 3 that the skewness of heating rate $\left(H_{\mathrm{r}}\right)$ is 1.507 , which indicates highly skewed data. It is worth mentioning here that combining the test data for specimens with wide range of heating rates varying from 0.5 to $20^{\circ} \mathrm{C} / \mathrm{min}$ in developing the residual strength models of HSC was similar to other published work in the literature [31, 33, 89]. HSC specimens of the compiled database used by Phan and Carino [33] were exposed to high temperatures at wide range of heating rates varying from 0.2 to $32^{\circ} \mathrm{C} / \mathrm{min}$. Aslani and Bastami [31] developed models for NSC and HSC using test data with heating rates varying from very low rates up to standard fire curve as per the ASTM E119 [87]. Also, Knaack et al. [89] developed compressive strength relationships for both NSC and HSC under elevated temperatures using published experimental data with heating rates ranging from 2 to $93.33^{\circ} \mathrm{C} / \mathrm{min}$. The concrete compressive strength at room temperature varies from the start of the range of HSC and includes even the ultrahighstrength concrete.

Figure 2 shows the breakup of the data with respect to the type of the test specimen, the type of coarse aggregate, and the concrete strength at room temperature $\left(f_{c, r}^{\prime}\right)$. It should be noted from Figure 2(c) that the breakup of the data for $f_{c, r}^{\prime}$ is based on the limits given in Eurocode 2: EN 1992-1-2 [4] (for the 55 MPa limit), and the model of Aslani and Bastami [31] (for both 55 and $80 \mathrm{MPa}$ limits). The limit of $100 \mathrm{MPa}$ was selected as an onset for ultrahighstrength concrete. The data cover cubes of 70,100 , and $150 \mathrm{~mm}$ and cylinders of $75 \times 150,100 \times 200$, and $150 \times 300 \mathrm{~mm}$. It is observed from Figure 2(a) that data for cubes $(57.5 \%)$ are slightly more than that of cylinders. Maximum data are for cubes of $100 \mathrm{~mm}$ size (41.5\%). It should be noted that even though the strength loss at high temperatures measured on cylinders may be greater than that measured on cubes as reported by Bamonte and Gambarova [90] (based on the data obtained from di Prisco et al. [91]) for temperatures beyond $400^{\circ} \mathrm{C}$, equations (1) and (2) are assumed to be valid for all range of elevated temperatures. This is due to the big variance in the sizes of cylinders and cubes used in this study which were not all covered by the data of di Prisco et al. [91]. Therefore, data of cubes and cylinders of different sizes were mixed in this study while developing residual strength models for HSC exposed to elevated temperatures. This was similar to other work published in the literature [31, 33, 89]. For example, Phan and Carino [33] compiled test data for HSC cylinders of height/diameter ratio less than $2(28 \times 52 \mathrm{~mm}$ and $57 \times 100 \mathrm{~mm}$ ) with HSC cylinders of the aspect ratio at least $2(51 \times 102 \mathrm{~mm}, 60 \times 180 \mathrm{~mm}, 75 \times 150 \mathrm{~mm}, 80 \times$ $300 \mathrm{~mm}, 100 \times 200 \mathrm{~mm}$, and $150 \times 300 \mathrm{~mm}$ ) along with HSC cubes of $100 \mathrm{~mm}$ size. The study of Aslani and Bastami [31] even combined the data of HSC cubes and cylinders of different sizes and aspect ratios with standard fire tests on large-scale reinforced HSC columns of dimensions $305 \times 305 \times 3810 \mathrm{~mm}$. Also, in the work of Knaack et al. [89], data of concrete cylinders and prisms with different sizes and aspect ratios were mixed to come up with compressive strength relationships for both NSC and HSC under elevated temperatures. As seen in Figure 2(b), the data of concrete having siliceous aggregates $(52 \%)$ more than that of calcareous aggregates $(36 \%)$. Even though a wide range of concrete compressive strength is included in the data (from 41.5 to $140.6 \mathrm{MPa}$ ), the data for the concrete strength greater than $100 \mathrm{MPa}$ are fairly low (5.7\%). As seen in Figure 2(c), about $40.0 \%$ of the data of concrete strength ranges from 55.1 to $80.0 \mathrm{MPa}$ with $32.12 \%$ data for lower strength ranging from 41.5 to $55 \mathrm{MPa}$, which is also clear from the positive skewness of 0.646 as seen in Table 3 .

Figure 3 shows the surface plot of normalized concrete strength (i.e., the ratio of the residual strength of concrete after high-temperature exposure to the concrete strength at room temperature) against two variables. One of the variables is the elevated temperature, $T$, and the remaining variables are taken in turn for the second. The use of siliceous or calcareous aggregates does not indicate any definite trend, as seen in Figure 3(a). The plots show the occurrence of random waves in the surface profiles especially in the low-temperature range for most of the variable combinations (Figures 3(b) to 3(e)). These waves are maximum in water-to-binder ratio, which may be owing to the hostile effects of superplasticizers. It is thus explicable that there is no definite trend of variation for different variables other than the exposure temperature, $T$.

Although there are some other variables such as moisture content, type of superplasticizer, and cooling regime that may affect the concrete strength, they were not taken into account due to the nonavailability of their values. It is worth noting that these variables are also omitted in the models available in the literature. 
TABLe 3: Statistics of input parameters (485 data points).

\begin{tabular}{lccccc}
\hline Statistical parameter & $\begin{array}{c}\text { Aggregate/binder } \\
\text { ratio, } a / b\end{array}$ & $\begin{array}{c}\text { Water/binder } \\
\text { ratio, } w / b\end{array}$ & $\begin{array}{c}\text { Heating rate, } \\
H_{\mathrm{r}}\left({ }^{\circ} \mathrm{C} / \mathrm{min}\right)\end{array}$ & $\begin{array}{c}\text { Elevated temperature, } \\
T\left({ }^{\circ} \mathrm{C}\right)\end{array}$ & $\begin{array}{c}\text { Concrete strength at room } \\
\text { temperature, } f_{\mathrm{c}, \mathrm{r}}^{\prime}(\mathrm{MPa})\end{array}$ \\
\hline Min. value & 0.82 & 0.13 & 0.50 & 50 & 41.5 \\
Max. value & 4.59 & 0.60 & 20.0 & 1200 & 140.6 \\
Mean & 2.29 & 0.36 & 5.78 & 479 & 67.3 \\
Standard deviation (SD) & 0.65 & 0.11 & 5.74 & 261 & 19.7 \\
Coefficient of variation (CV) (\%) & 28.2 & 31.2 & 99.4 & 54.5 & 29.2 \\
Skewness & 0.232 & 0.564 & 1.507 & 0.529 & 0.646 \\
Kurtosis & -0.042 & -0.569 & 1.235 & -0.255 & 0.263 \\
\hline
\end{tabular}
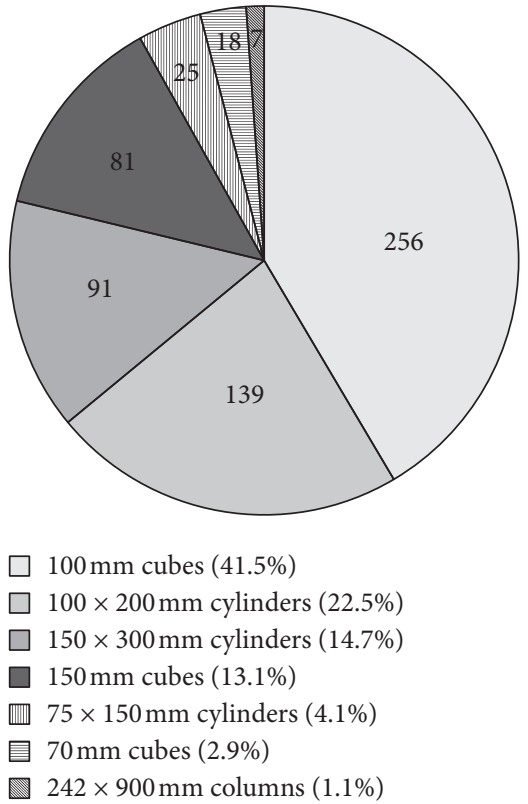

(a)

$242 \times 900 \mathrm{~mm}$ columns $(1.1 \%)$
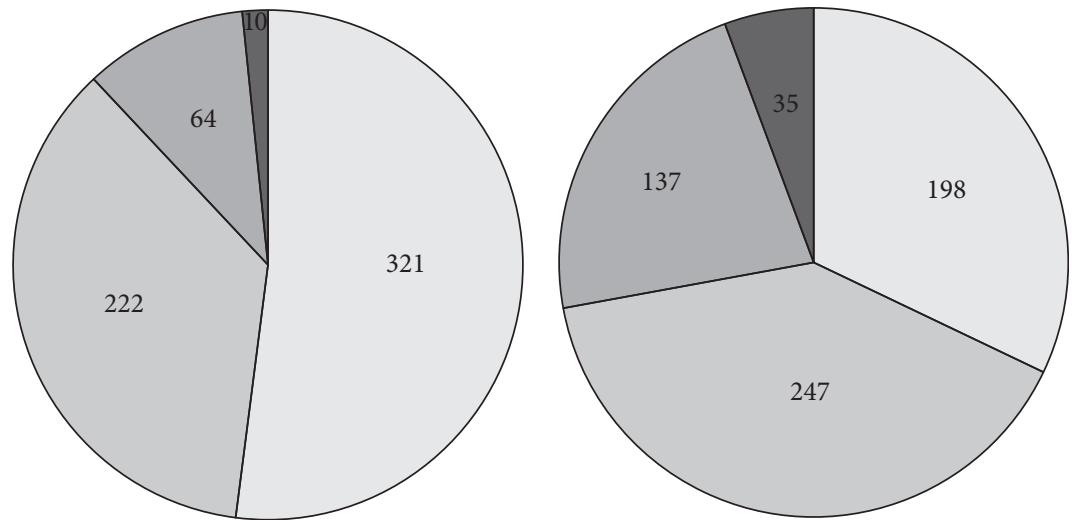

$\square$ Siliceous (52.0\%)

$\square$ 41.5-55 $\mathrm{MPa}(32.1 \%)$

Calcareous (36.0\%)

Not available (10.4\%)

Silico-calcareous (1.6\%)

$\square$ 55.1-80 MPa (40.0\%)

$\square$ 80.1-100 MPa (22.2\%)

$\square>100 \mathrm{MPa}(5.7 \%)$

(b)

(c)

Figure 2: Distribution of all 617 HSC data points with respect to (a) type of the test specimen, (b) type of the coarse aggregate, and (c) compressive strength of concrete at room temperature $\left(f_{\mathrm{c}, \mathrm{r}}^{\prime}\right)$.

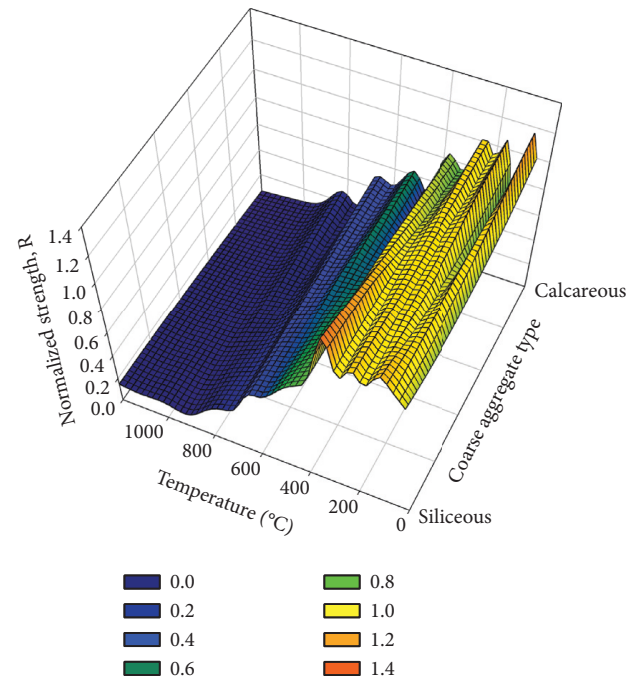

(a)

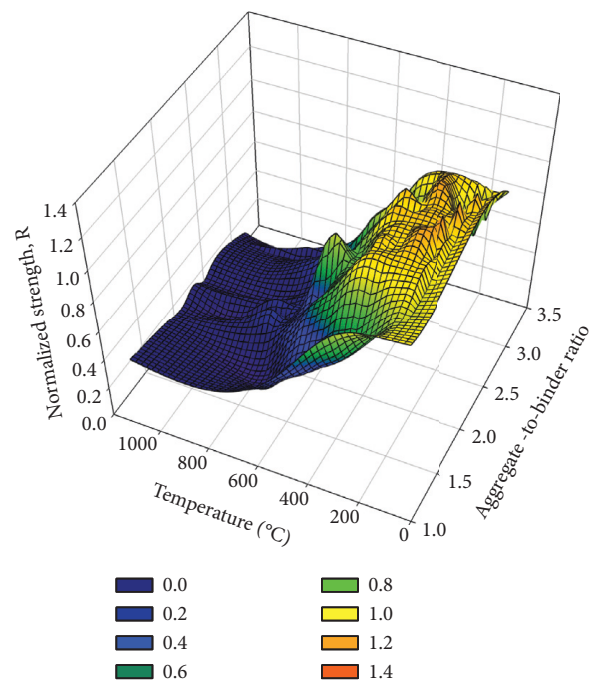

(b)

Figure 3: Continued. 


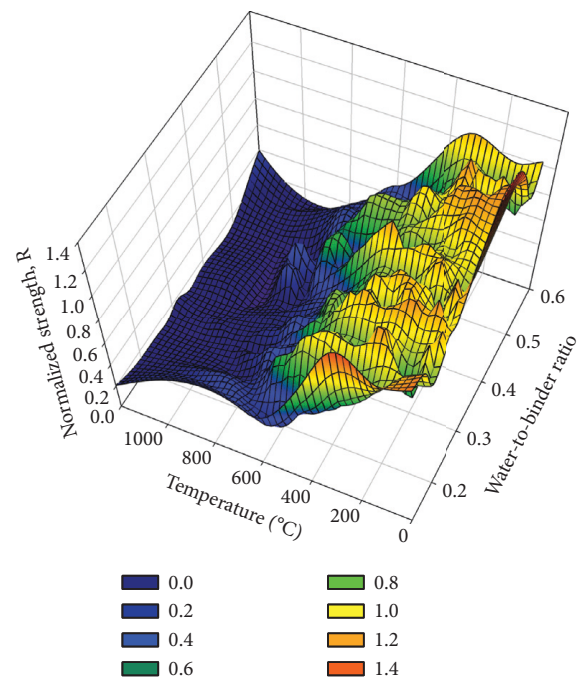

(c)

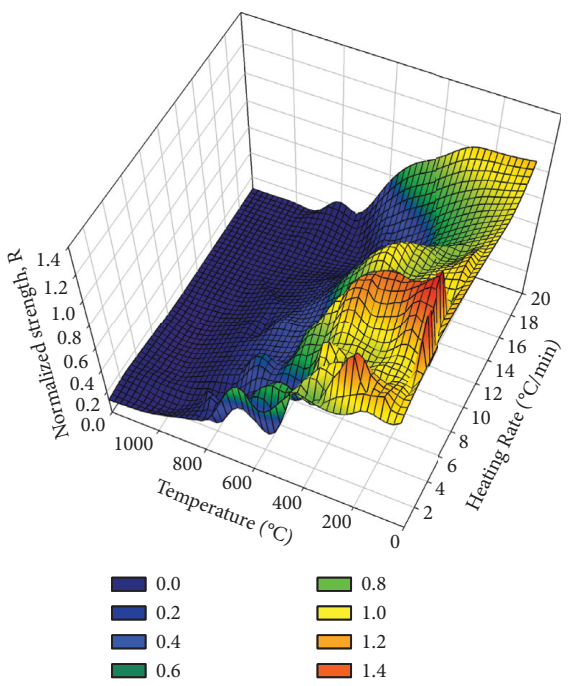

(d)

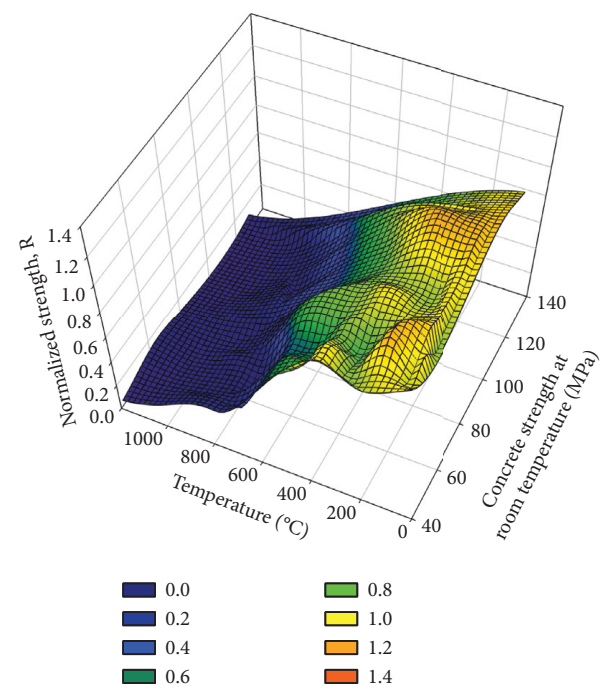

(e)

FIGURE 3: Normalized concrete strength as functions of exposure temperature and (a) type of coarse aggregate, (b) aggregate-to-binder ratio, (c) water-to-binder ratio, (d) heating rate, and (e) concrete strength at room temperature.

\section{Sensitivity Analysis}

The models based on the artificial neural network (ANN) have been detailed in several studies [92-99]. The main idea of ANN models originates from forming a mathematical relation between the dependent and independent variables by training the models using available data [94-96]. Sensitivity tests were performed using artificial neural networks (ANN) to assess the relative importance of the variables in the estimation of residual strength of HSC after being exposed to elevated temperature. In the ANN modeling, the input independent variables were aggregateto-binder ratio, $a / b$; water-to-binder ratio, $w / b$; heating rate in ${ }^{\circ} \mathrm{C} / \mathrm{min}, H_{r}$; exposure temperature in ${ }^{\circ} \mathrm{C}, T$; and concrete strength at room temperature in $\mathrm{MPa}, f_{\mathrm{c}, \mathrm{r}}^{\prime}$. The output dependent variable is the ratio of residual strength of HSC after high temperature exposure, $f_{\mathrm{c}, \mathrm{T}}^{\prime}$, to $f_{\mathrm{c}, \mathrm{r}}^{\prime}$. The network architecture of ANN contains twelve neurons and one hidden layer. The tansig transfer function was employed along with the back propagation (BP) formulation [92-94].

Tan-sigmoid transfer function:

$$
y_{j}=f\left(\sum_{i} W_{i j} x_{i}+b_{j}\right)=\frac{2}{1+e^{-2\left(\sum_{i} W_{i j} x_{i}+b_{j}\right)}}-1 \text {, }
$$

where $x$ and $y$ are the independent and dependent variables, respectively, whereas $W$ and $b$ are the weight and biases. Subscripts $i$ and $j$ represent number of independent variables and the number of neurons, respectively. The values of $W$ and $b$, of the above equation, were estimated in such a way that the energy function is minimized. The architecture of the neural network employed in the study is given in Figure 4. The data were processed through three phases of ANN modeling, 


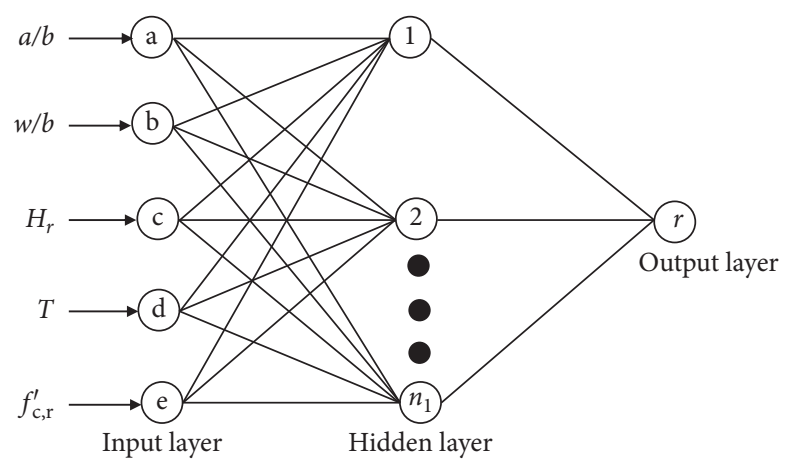

FIGURe 4: Neural network model involving single hidden layer employed for sensitivity analysis $\left(n_{1}=\right.$ number of neuros $=12$ in this study).

namely, training, validation, and testing, and a discrete data set was used for each phase. It is worth mentioning here that ideal distribution of data between testing/validation and training does not exist. However, a review of literature shows that the percentage of data used for training varies from $67 \%$ to $90 \%$, and the remaining data are used for validation and testing [89-95]. In the present study, the training was done using $2 / 3 \mathrm{rd}$ of the data, whereas the validation and testing were performed using the remaining $33 \%$ data $[92,93]$. The data for the three phases were selected randomly.
The sensitivity analysis was carried out via removing each input at a time from the model. The effect of elimination of a variable from the model on the calculation of residual concrete strength after high-temperature exposure was determined in terms of the error estimate parameters listed in Table 4. These parameters include mean percent error (MPE), mean absolute percent error (MAPE), root mean square error (RMSE), and correlation coefficient (CC). They are defined in the following formulae:

$$
\begin{aligned}
\text { MPE } & =\frac{1}{n} \sum_{1}^{n}\left(\frac{R_{\mathrm{th}}-R_{\exp }}{R_{\exp }} \times 100\right), \\
\mathrm{MAPE} & =\frac{1}{n} \sum_{1}^{n}\left|\left(\frac{R_{\mathrm{th}}-R_{\exp }}{R_{\exp }} \times 100\right)\right|, \\
\mathrm{RMSE} & =\frac{1}{n} \sqrt{\sum_{1}^{n}\left(R_{\mathrm{th}}-R_{\exp }\right)^{2},} \\
\mathrm{CC} & =\frac{1}{n-1}\left[\frac{\sum_{1}^{n}\left(R_{\exp }-\left(\sum_{1}^{n} R_{\exp } / n\right)\right)}{\left.\left.\left.\sqrt{\left(\sum_{1}^{n}\left(R_{\exp }-\left(\left(\sum_{1}^{n} R_{\exp }\right) / n\right)\right)^{2}\right) /(n-1)} \cdot \sqrt{\left(\sum_{1}^{n} R_{\mathrm{th}}-\left(\left(\sum_{1}^{n} R_{\mathrm{th}} / n\right)\right)\right.} \cdot R_{\mathrm{th}}\right) / n\right)^{2}\right) /(n-1)}\right],
\end{aligned}
$$

where $n$ is the number of test specimens; $R_{\exp }$ is the measured normalized concrete strength, which is the ratio of the measured residual concrete strength after high temperature exposure in $\mathrm{MPa}\left(f_{\mathrm{c}, \mathrm{T}}^{\prime}\right)_{\exp }$ to the measured concrete strength at room temperature in $\mathrm{MPa}\left(f_{\mathrm{c}, \mathrm{r}}^{\prime}\right)_{\text {exp }}$; and $R_{\mathrm{th}}$ is the predicted normalized concrete strength. The positive value of MPE means overestimation, whereas its negative value shows underestimation. However, the desired value of MPE is zero. For the best predictive model, the error parameters MPE, MAPE, and RMSE should be zero, while CC should be unity. The value of epochs was input as 100 .

The output results reported in Table 4 were reached after 100 successful runs of ANN for all cases. Although $T$ is clearly the most sensitive variable, the remaining variables show low level of sensitivity which is almost the same for all. The removal of temperature, $T$, being the most sensitive parameter, brings the value of CC down from 0.95 to 0.51 . As observed from Table 1, most of the models of codes and researchers for the assessment of residual concrete strength only incorporate $T$ except Eurocode 2 [4] and Aslani and Bastami [31] where separate equations are suggested for different ranges of concrete strength, $f_{\mathrm{c}, \mathrm{r}}^{\prime}$. Nevertheless, the effect of its removal has almost no effect on error estimated with RMSE increasing from 0.10 to 0.11 and $C C$ reducing from 0.95 to 0.94 . Keeping only $T$ depicts small reduction in CC from 0.95 to 0.90 . Moreover, the effect of individual elimination of rest of the variables on error estimates is almost insignificant. Therefore, the 
TABLE 4: Sensitivity analysis with feedforward back propagation for different sets of input variables.

\begin{tabular}{lcccc}
\hline Input variables & MPE & MAPE & RMSE & CC \\
\hline All & 1.36 & 14.92 & 0.10 & 0.95 \\
No $a / b$ & 2.21 & 15.05 & 0.10 & 0.95 \\
No $w / b$ & 3.26 & 15.96 & 0.12 & 0.93 \\
No $H_{\mathrm{r}}$ & 2.12 & 16.77 & 0.11 & 0.93 \\
No $T$ & 27.63 & 53.42 & 0.27 & 0.51 \\
No $f_{c, \mathrm{r}}^{\prime}$ & 4.10 & 15.63 & 0.11 & 0.94 \\
Only $T$ & 6.83 & 19.47 & 0.14 & 0.90 \\
\hline
\end{tabular}

MPE, mean percent error; MAPE, mean absolute percent error; RMSE, root mean square error; CC, correlation coefficient.

establishment of the predictive model using Talone may be acceptable.

\section{Regression Models}

As regression-based models are usually in the form of equations relating the independent variable with one or more of dependent variables, they are most favored by codes, standards, and design guidelines. These models are also simple to be used by practicing engineers. The goal of this research is to devise simple regression-based models to be included in fire-design codes and guidelines for the assessment of residual compressive strength of HSC after its exposure to high temperature or fire. Accordingly, the ANN models discussed in the previous section were not assessed further and thus were not compared with existing models available in the literature, as the focus will be on regressionbased models.

As reported in the models available in the literature, for NSC, the siliceous-aggregate concrete has better resistance to high temperature (unstressed residual) as compared to the calcareous-aggregate concrete [5]. However, for HSC, only the model proposed by Aslani and Bastami [31] differentiates between the aggregate types. However, the effect of type of aggregate on HSC is not evidently identified in other models. In fact, as mentioned previously, the effect of type of aggregate (calcareous or siliceous) is considered in the model of Eurocode 2 [4] for concrete having $f_{\mathrm{c}, \mathrm{r}}^{\prime}<55.0 \mathrm{MPa}$; however, it is not taken into account for HSC having $f_{\mathrm{c}, \mathrm{r}}^{\prime} \geq$ 55.0 MPa. As seen from Figure 2(b), 52\% and 36\% of the compiled data were for HSC with siliceous and calcareous aggregates, respectively; however, the remaining data were for either unknown type of aggregate or HSC with silico-calcareous aggregate. Therefore, in the development of regression-based models in this study, the compiled data were not separated based on the type of aggregate as the use of siliceous or calcareous aggregates did not indicate any definite trend, as seen from the surface plot in Figure 3(a) and also for the models to be applicable for the data for which type of aggregate is unidentified.

A regression model (Model 1) of the following form was used by employing all variables for assessing the residual compressive strength of HSC:

$$
R= \begin{cases}1, & \text { for } T \leq 50^{\circ} \mathrm{C}, \\ 1+\left[C 1\left(\frac{T-50}{100}\right)+C 2\left(\frac{T-50}{100}\right)^{2}+C 3\left(\frac{T-50}{100}\right)^{3}\right] & \\ \times\left(\frac{a}{b}\right)^{C 4} \times\left(\frac{w}{b}\right)^{C 5} \times\left(H_{\mathrm{r}}\right)^{C 6} \times\left(\frac{f_{\mathrm{c}, \mathrm{r}}^{\prime}}{41.4}\right)^{C 7}, & \text { for } T>50^{\circ} \mathrm{C},\end{cases}
$$

where $R$ is the normalized concrete strength, which is the ratio of the residual concrete strength after being exposed to the elevated temperature in $\mathrm{MPa}\left(f_{\mathrm{c}, \mathrm{T}}^{\prime}\right)$ to the concrete strength at room temperature in $\mathrm{MPa}\left(f_{\mathrm{c}, \mathrm{r}}^{\prime}\right) ; T$ is the elevated temperature in ${ }^{\circ} \mathrm{C} ; a / b$ is the aggregate-to-binder ratio; $w / b$ is the water-tobinder ratio; and $H_{\mathrm{r}}$ is the heating rate in ${ }^{\circ} \mathrm{C} / \mathrm{min}$.

The regression analysis was used to obtain the model parameters $C 1$ to $C 7$, which were found as $0.018,-0.027$, $0.002,-0.036,-0.168,-0.006$, and -0.092 , respectively (Table 5). The scatter in the prediction by this model is shown in Figure 5(a). It is worth mentioning here that the values of all parameters were not available for all data points, thus the above model was developed based on 460 data points for which the values of all parameters were available.

The above model was simplified by replacing the cubic polynomial of elevated temperature, $T$, by the power function. The revised model (Model 2) is given by

$$
R= \begin{cases}1, & \text { for } T \leq 50^{\circ} \mathrm{C}, \\ 1-C 1\left(\frac{T-50}{100}\right)^{C 2} \times\left(\frac{a}{b}\right)^{C 3} \times\left(\frac{w}{b}\right)^{C 4} & \\ \times\left(H_{r}\right)^{C 5} \times\left(\frac{f_{c, r}^{\prime}}{41.4}\right)^{C 6}, & \text { for } 50^{\circ} C<T \leq 1100^{\circ} \mathrm{C}, \\ 0, & \text { for } T>1100^{\circ} \mathrm{C} .\end{cases}
$$

The values of the model parameters $C 1$ to $C 6$ are given in Table 5, and the scatter in the prediction using this model is plotted in Figure 5(b).

A comparison of the predictive models, in terms of the error estimates, is given in Table 6. The error estimates used for the evaluation of different models are MPE, MAPE, $R M S E$, percent data for error within $15 \%$, and percentage error enveloping $80 \%$ of the data. It is observed from the table that there is marginal deterioration in the error estimates when polynomial function of $T$ used in Model 1 is replaced by power function in Model 2 with the MAPE, RMSE, and percentage error enveloping $80 \%$ data increasing from 20.04 to 26.68 , from 0.14 to 0.15 , and from 31.8 to 34.4 , respectively. On the contrary, there is small reduction in the $M P E$ and percent data for error within 15\% from 6.70 to 5.88 and from 54 to 45 , respectively. Thus the overall effect of this replacement is almost negligible.

As the sensitivity analysis highlighted the significance of models containing the elevated temperature, $T$, alone, another regression model (Model 3) was developed as a function of $T$, thus eliminating all other variables: 
TABle 5: Values of constants $C 1$ to $C 7$ for the proposed regression models.

\begin{tabular}{|c|c|c|c|c|c|c|}
\hline Constant & Model 1 & Model 2 & Model 3 & Model 4 & $\begin{array}{c}\text { Model } \\
5\end{array}$ & Model 6 \\
\hline$C 1$ & 0.018 & 0.041 & 0.021 & 0.053 & -0.2074 & 0.234 \\
\hline$C 2$ & -0.027 & 1.331 & -0.030 & 1.254 & 0.0150 & 0.644 \\
\hline$C 3$ & 0.002 & -0.120 & 0.002 & - & -0.0005 & - \\
\hline$C 4$ & -0.036 & -0.267 & - & - & - & - \\
\hline C5 & -0.168 & 0.021 & - & - & - & - \\
\hline C6 & -0.006 & -0.239 & - & - & - & - \\
\hline$C 7$ & -0.092 & - & - & - & - & - \\
\hline
\end{tabular}

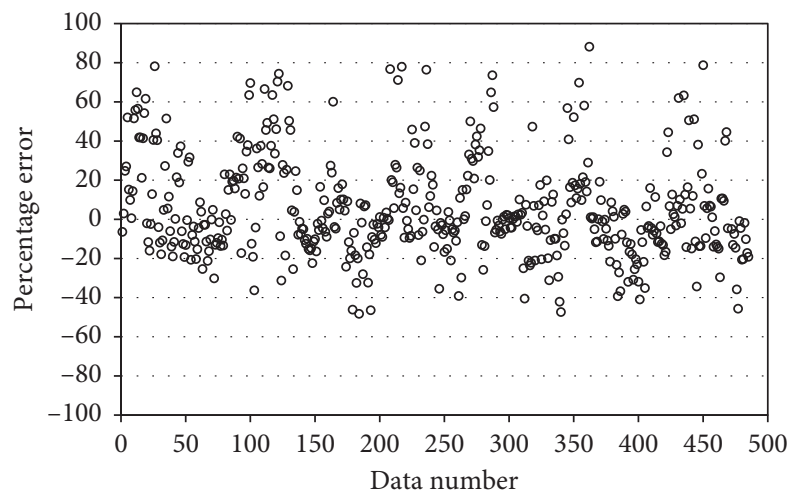

(a)

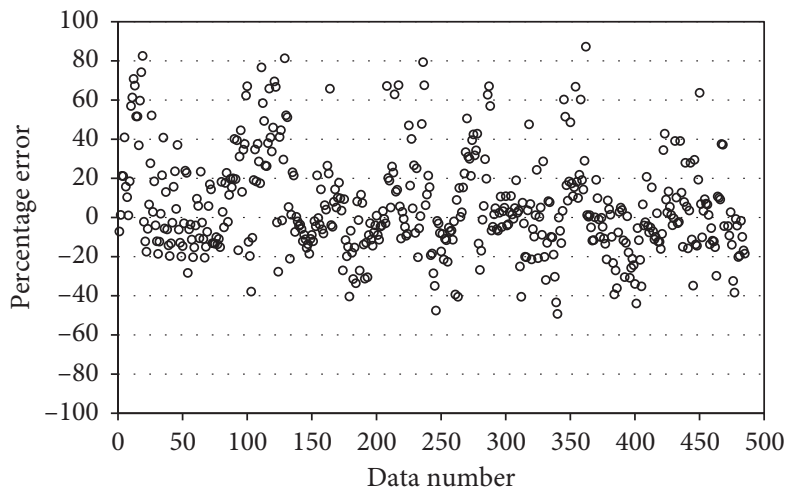

(c)

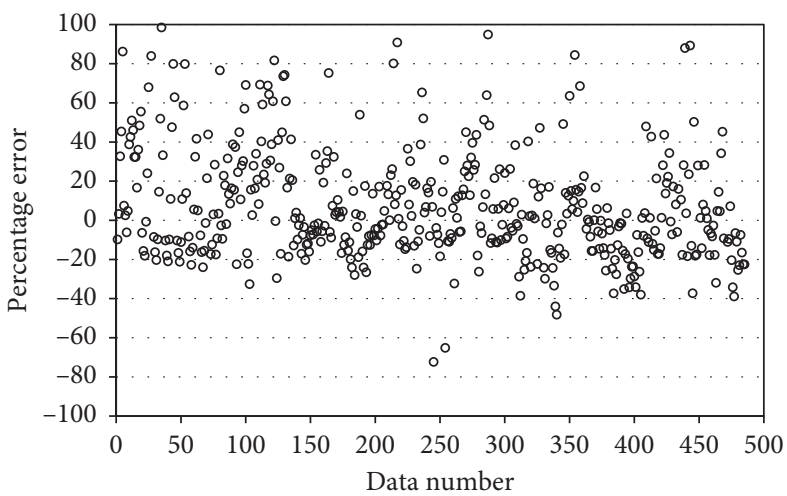

(b)

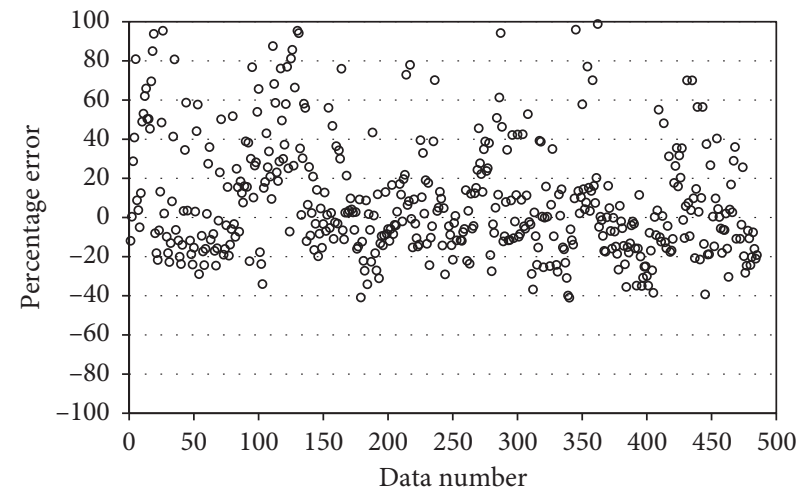

(d)

Figure 5: Percentage error in the prediction of normalized strength of HSC for individual data points using (a) regression Model 1, (b) regression Model 2, (c) regression Model 3, and (d) regression Model 4.

TABLE 6: Error estimates for different predictive models.

\begin{tabular}{lcccc}
\hline \multirow{2}{*}{ Parameter for error estimate } & \multicolumn{3}{c}{ Normalized concrete strength $\left(R=f_{\mathrm{c}, \mathrm{T}}^{\prime} / f_{\mathrm{c}, \mathrm{r}}^{\prime}\right)$} \\
& Regression Model 1 & Regression Model 2 & Regression Model 3 & Regression Model 4 \\
\hline Mean percent error (MPE) & 6.70 & 5.88 & 6.71 & 5.66 \\
Mean absolute percent error (MAPE) & 20.04 & 26.68 & 19.95 & 0.14 \\
Root mean square error (RMSE) & 0.14 & 0.15 & 55 & 0.15 \\
Percent data for error within 15\% & 54 & 45 & 30.8 & 46 \\
Percentage error enveloping 80\% data & 31.8 & 34.4 & 38.4 \\
\hline
\end{tabular}

$R= \begin{cases}1, & \text { for } T \leq 50^{\circ} \mathrm{C}, \\ 1+C 1\left(\frac{T-50}{100}\right)+C 2\left(\frac{T-50}{100}\right)^{2}+C 3\left(\frac{T-50}{100}\right)^{3}, & \text { for } T>50^{\circ} \mathrm{C} .\end{cases}$
The above model is a cubic polynomial for whole range of the exposure temperature with the model parameters given in Table 5. Figure 5(c) shows the scatter in the prediction of residual concrete compressive strength using this model. 
Another simplified form of the above model was tried (Model 4) in which the cubic polynomial of $T$ was replaced by the power function:

$$
R= \begin{cases}1, & \text { for } T \leq 50^{\circ} \mathrm{C} \\ 1-C 1\left(\frac{T-50}{100}\right)^{C 2}, & \text { for } 50^{\circ} \mathrm{C}<\mathrm{T}<1100^{\circ} \mathrm{C} \\ 0, & \text { for } T \geq 1100^{\circ} \mathrm{C} .\end{cases}
$$

The model parameters $C 1$ and $C 2$ obtained by regression analysis are given in Table 5 . The scatter in the assessment of residual compressive strength of concrete using this model is plotted in Figure 5(d). The effect of model simplification involving the replacement of cubic polynomial of $T$ by the power function on error estimates is marginal with some parameters such as MAPE, RMSE, and percent error enveloping $80 \%$ data showing small deterioration, whereas the remaining two error estimates (i.e., $M P E$ and percent data for error within 15\%) show nominal improvement.

Figure 6 shows the $T$ versus $R$ plots along with the prediction models given by using equations (7) and (8) (i.e., Model 3 and Model 4). It is discernable from the figure that there is no definite trend for different percentage ranges of temperature and thus the development of above models for the whole range of temperature is justified.

Figure 7 shows a comparison between the normalized strength of HSC assessed by proposed predictive models with experiments. The histogram of error for the four predictive models is shown in Figure 8. It is indicated that the errors in prediction of the normalized strength of HSC by Model 1 is almost the same as those predicted using Model 3 and errors estimated using predictive Model 2 are almost identical to those predicted using Model 4. The values of the statistical indicators such as mean, $S D, C V, C C$, and $R^{2}$ for the proposed predictive models are listed in Table 7 , which shows good correlation for all the four models with marginal difference. It is observed from the error estimates given in Table 6 and the statistical indicators listed in Table 7 that the models developed based on the temperature Talone (i.e., Model 3 and Model 4) are equally good as the remaining two models. Thus the incorporation of the variables other than temperature, $T$, has almost negligible effect on the prediction of $R$, which was also evident in the sensitivity analysis. It is due to this reason that Model 3 and Model 4 will be used for the development of the proposed design models.

\section{New Proposed Design Models}

For making conservative estimates of the residual compressive strength of concrete after high-temperature exposure, the regression models given by using equations (7) and (8) (i.e., Model 3 and Model 4) are transformed to the empirical design models such that $95 \%$ of the data lies above the proposed equations. The proposed design models are therefore given by Model 5:

$$
R= \begin{cases}1, & \text { for } T \leq 50^{\circ} \mathrm{C}, \\ 1+C 1\left(\frac{T-50}{100}\right)+C 2\left(\frac{T-50}{100}\right)^{2} & \\ +C 3\left(\frac{T-50}{100}\right)^{3}, & \text { for } 50<T<1000^{\circ} \mathrm{C}, \\ 0, & \text { for } T \geq 1000^{\circ} \mathrm{C},\end{cases}
$$

and Model 6:

$$
R= \begin{cases}1, & \text { for } T \leq 50^{\circ} \mathrm{C}, \\ 1-C 1\left(\frac{T-50}{100}\right)^{C 2}, & \text { for } 50^{\circ} \mathrm{C}<T<1000^{\circ} \mathrm{C}, \\ 0, & \text { for } T \geq 1000^{\circ} \mathrm{C} .\end{cases}
$$

The $T$ versus $R$ plots of the two proposed design models (i.e., Model 5 and Model 6) are shown in Figure 6, which shows that most of the data points lie above the curves given by the two models. For temperatures of $1000^{\circ} \mathrm{C}$ and above, the values of $R$ are taken as zero for the two models, which is a conservative estimate for some of the experimental results. Figure 9 depicts a comparison between the normalized strength of HSC assessed by proposed design models with experiments. As seen from the figure, nonconservative predictions of $5.6 \%$ and $4.7 \%$ were calculated for Model 5 and Model 6, respectively. Figures 10 and 11 show a comparison between the normalized strength of HSC assessed by models of codes and researchers with experiments, respectively.

Figure 12 presents the spread of quartiles of the deviations in the assessment of residual concrete strength. A global view of the scatter in the assessment of residual concrete strength using different models is provided by this plot. In this figure, nonconservative assessment (with predicted values being greater than the experimental ones) is given by the positive deviation. The upper and lower bounds of the deviations are represented, respectively, by the top and bottom ends of the bars. This plot will help in identifying the best performing model for which the full height of deviation bar should be under the line of zero deviation, and the $2^{\text {nd }}$ and $3^{\text {rd }}$ quartiles as well as the total height of vertical bar are minimum. The proposed design models (Model 5 and Model 6) are the ones to meet all these favorite ideal features as evident from Figure 12.

The design models were evaluated on the basis of the mean, $S D, C V, C C$, and $R^{2}$. Table 7 provides the values of these parameters. The table also enlists $5^{\text {th }}$ percentile value and the percentage of nonconservative data. For the best design model, $S D$ and $C V$ should be small, whereas $C C$ and $R^{2}$ should be close to unity. Moreover, the mean value should be more than 1; however, it should be close to unity. Also, 


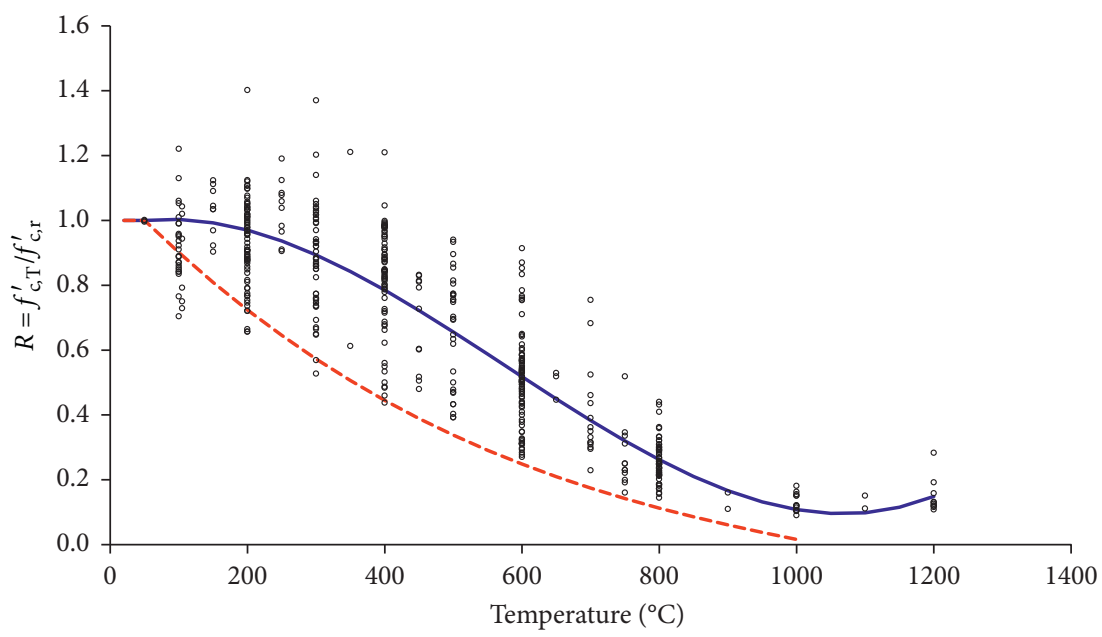

- Data points

— Model 3 (predictive)

-- Model 5 (design)

(a)

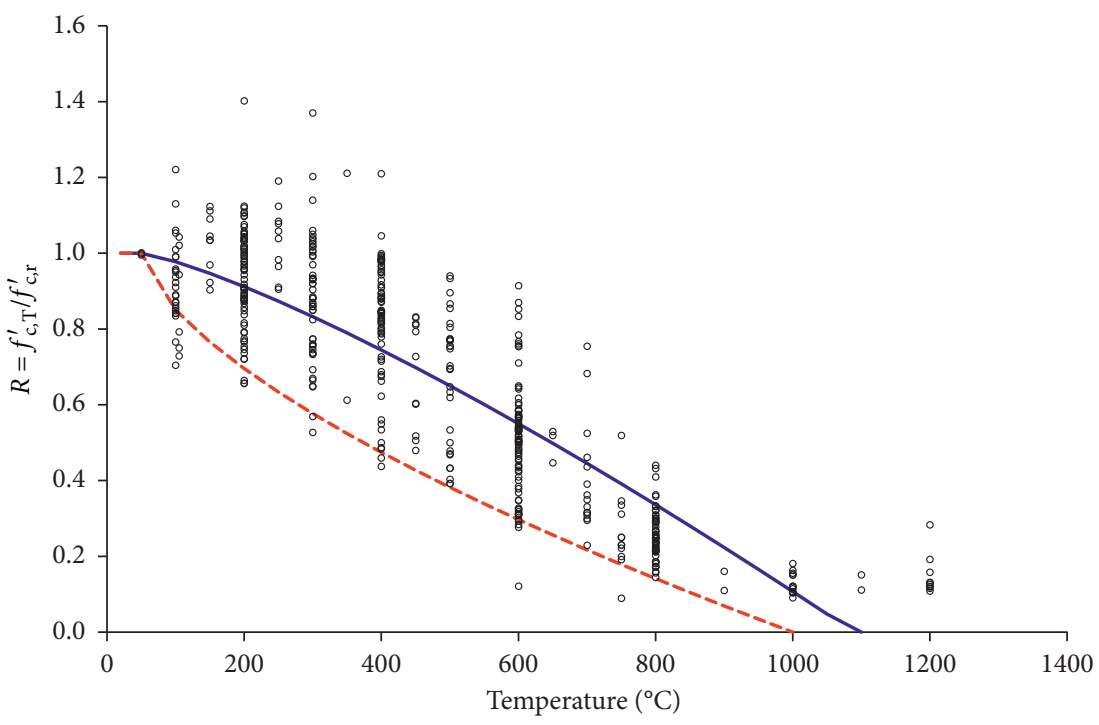

- Data points

- Model 4 (predictive)

- - Model 6 (design)

(b)

Figure 6: Performance of the proposed models in comparison with experiments: (a) Model 3 and Model 5 and (b) Model 4 and Model 6.

the nonconservative data points should be negligible and the $5^{\text {th }}$ percentile should be at least 1.0 .

Among the three different code models, ACI 216.1-07 [5] is better than others. Moreover, all the three code models are nonconservative; however, the nonconservative data for the model developed by ACI 216.1-07 [5] are low which is $17.9 \%$. The model of the ASCE Manual [6] is the most nonconservative with $66.0 \%$ nonconservative data. Among the researchers' design models, the model of Phan and Carino [33] is the best with the nonconservative data of $7.6 \%$, whereas the nonconservative data of other models vary from $12.4 \%$ to $41.4 \%$. Although the nonconservative data for Phan and Carino [33] model are close to the proposed models, the error estimates of the model are significantly higher. It is explicable from Table 7 that the proposed regression-based design models (i.e., Model 5 and Model 6) are better than other models. The value of the $5^{\text {th }}$ percentile for both of the proposed design models is 1.00 , thus satisfying the target.

As only $6.2 \%$ of the data is for $f_{c, r}^{\prime}$ greater than $100 \mathrm{MPa}$, the proposed design formulae should be applicable only to HSC of compressive strength not exceeding $100 \mathrm{MPa}$. Moreover, the maximum heating rate of the experimental data $\left(20{ }^{\circ} \mathrm{C} / \mathrm{min}\right)$ is quite less than that of standard fire [86-88]. Although the effect of the heating rate is found to be insignificant, this conclusion is based on the data of low 


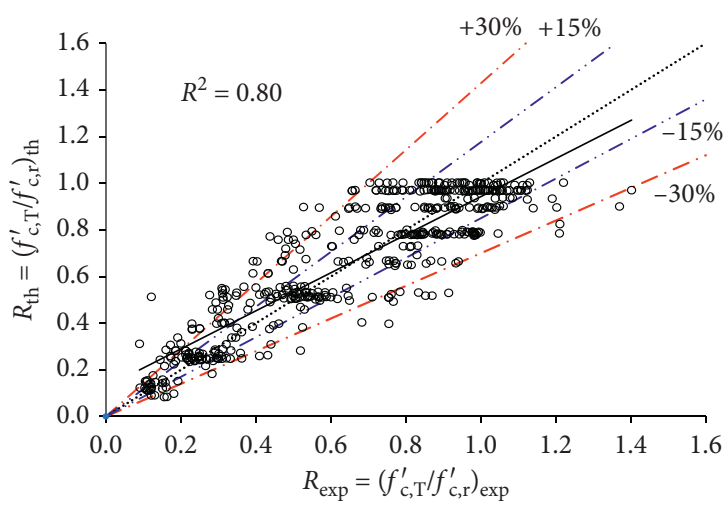

- Data points

.......... Experiment $=$ predicted

_ Best linear fit

(a)

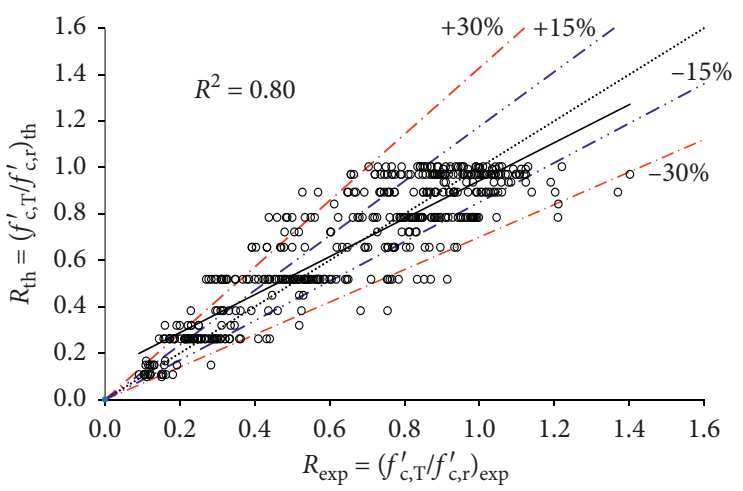

- Data points

.......... Experiment $=$ predicted

— Best linear fit

(c)

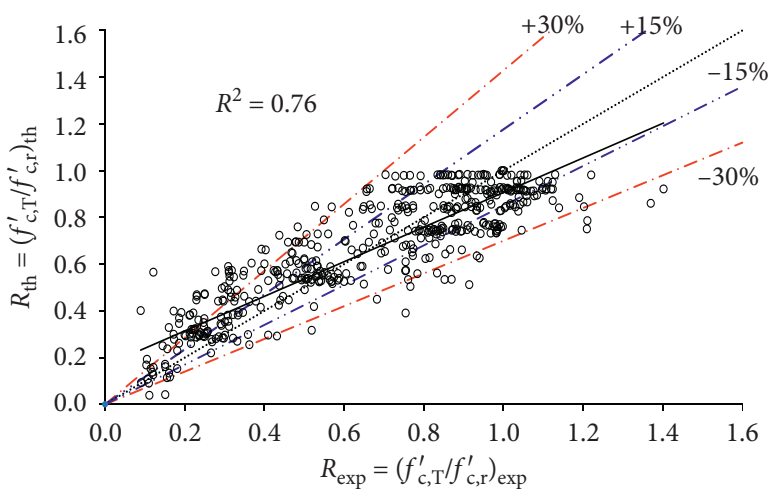

- Data points

.......... Experiment $=$ predicted

— Best linear fit

(b)

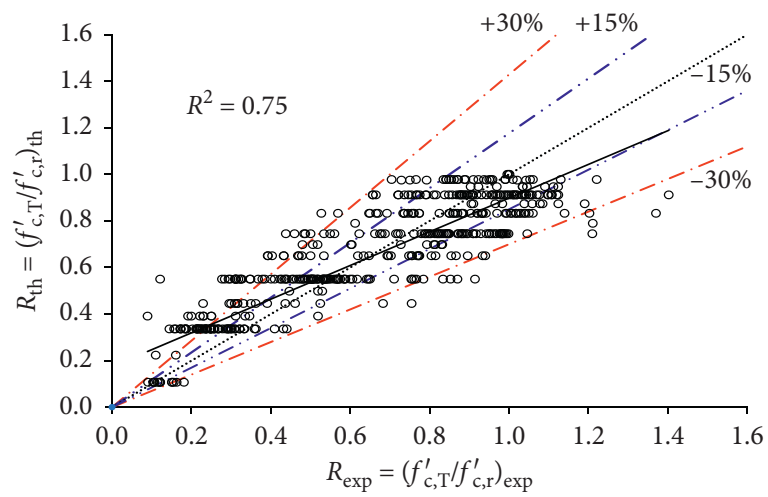

- Data points

…….. Experiment $=$ predicted

_ Best linear fit

FIGURE 7: Comparison of normalized strength of HSC predicted by the proposed predictive models with experiment: (a) regression Model 1, (b) regression Model 2, (c) regression Model 3, and (d) regression Model 4.

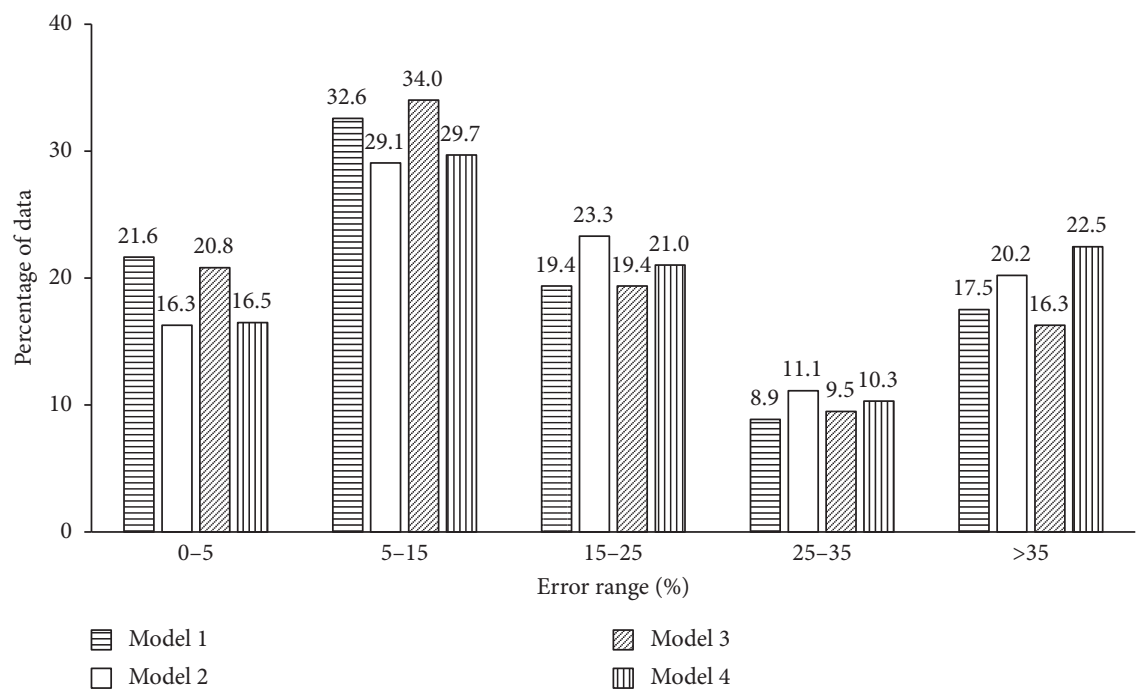

FIgURE 8: Histogram of error in the prediction of residual strength of concrete by the regression predictive models. 
TABLE 7: Statistical parameters for the assessment of models (485 data points).

\begin{tabular}{|c|c|c|c|c|c|c|c|c|c|}
\hline \multirow{2}{*}{ Model } & \multicolumn{8}{|c|}{ Statistical parameters for experimental to predicted ratio } & \multirow{2}{*}{ Nonconservative data (\% } \\
\hline & Mean & SD & $\mathrm{CV}(\%)$ & $5^{\text {th }}$ percentile value & Min. value & Max. value & $\mathrm{CC}$ & $R^{2}$ & \\
\hline \multicolumn{10}{|l|}{ Predictive models } \\
\hline Regression Model 1 & 1.00 & 0.24 & 23.9 & 0.63 & 0.24 & 1.93 & 0.89 & 0.80 & - \\
\hline Regression Model 2 & 0.99 & 0.28 & 28.7 & 0.59 & 0.21 & 3.61 & 0.87 & 0.76 & - \\
\hline Regression Model 3 & 1.00 & 0.24 & 23.6 & 0.62 & 0.23 & 1.97 & 0.89 & 0.80 & - \\
\hline Regression Model 4 & 0.98 & 0.25 & 25.3 & 0.57 & 0.22 & 1.69 & 0.87 & 0.75 & - \\
\hline \multicolumn{10}{|l|}{ Design models } \\
\hline Regression Model 5 & 1.77 & 0.59 & 33.5 & 1.00 & 0.49 & 4.33 & 0.84 & 0.70 & 5.6 \\
\hline Regression Model 6 & 1.60 & 0.44 & 27.6 & 1.00 & 0.41 & 3.48 & 0.85 & 0.72 & 4.7 \\
\hline Eurocode 2: EN 1992-1-2 [4] & 1.31 & 0.80 & 60.7 & 0.68 & 0.27 & 15.09 & 0.83 & 0.69 & 25.8 \\
\hline ACI $216.1-07$ [5] & 1.44 & 1.10 & 76.4 & 0.81 & 0.36 & 14.54 & 0.87 & 0.76 & 17.9 \\
\hline ASCE Manual [6] & 0.94 & 0.31 & 32.6 & 0.50 & 0.19 & 2.50 & 0.87 & 0.75 & 66.0 \\
\hline Kodur et al. [29] & 1.23 & 0.42 & 34.0 & 0.71 & 0.26 & 6.42 & 0.88 & 0.78 & 19.4 \\
\hline Nielsen et al. [30] & 1.67 & 1.99 & 119.8 & 0.68 & 0.26 & 9.71 & 0.89 & 0.79 & 31.1 \\
\hline Aslani and Bastami [31] & 1.08 & 0.60 & 55.4 & 0.15 & 0.07 & 3.60 & 0.17 & 0.03 & 41.4 \\
\hline Choe et al. [32] & 1.58 & 0.96 & 60.9 & 0.90 & 0.38 & 9.05 & 0.88 & 0.77 & 12.4 \\
\hline Phan and Carino [33] & 1.57 & 0.90 & 57.5 & 0.91 & 0.40 & 10.37 & 0.89 & 0.79 & 7.6 \\
\hline Hertz [34] & 2.15 & 1.95 & 90.7 & 0.80 & 0.63 & 10.00 & 0.87 & 0.75 & 18.6 \\
\hline
\end{tabular}

$\mathrm{SD}$, standard deviation; $\mathrm{CV}$, coefficient of variation; CC, coefficient of correlation; $R^{2}$, coefficient of determination.

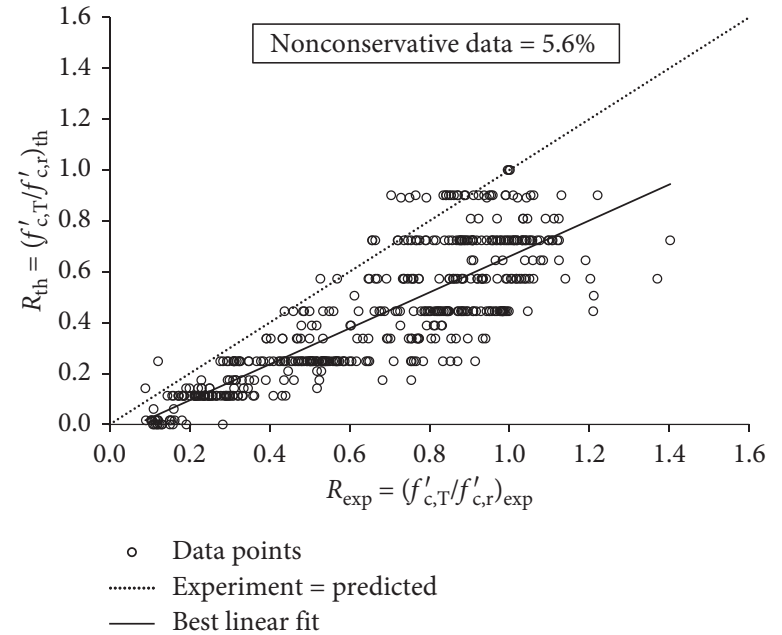

(a)

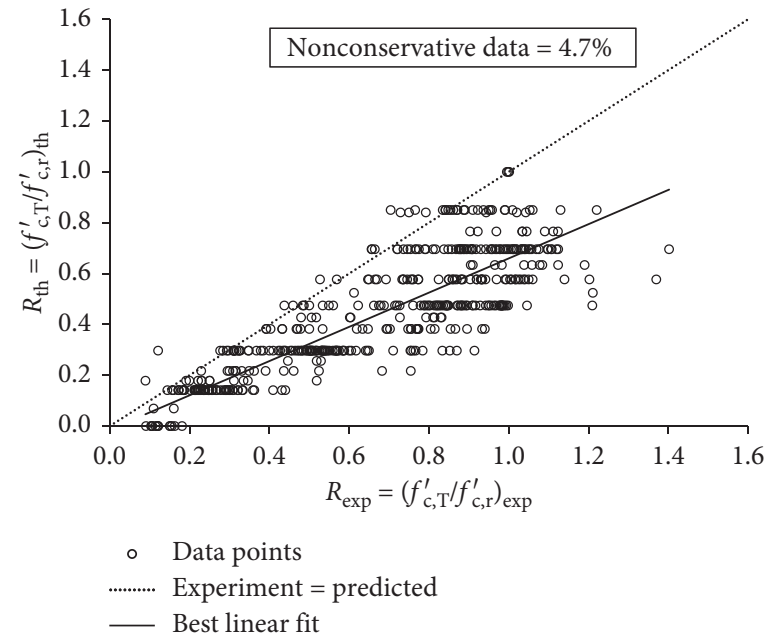

(b)

FIGURE 9: Comparison of normalized strength of HSC predicted by the proposed design models with experiment: (a) regression Model 5 and (b) regression Model 6.

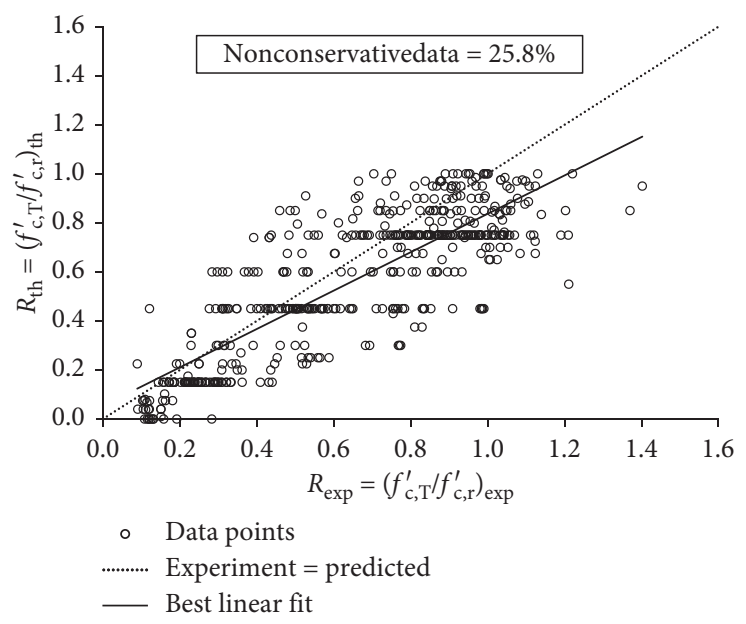

(a)

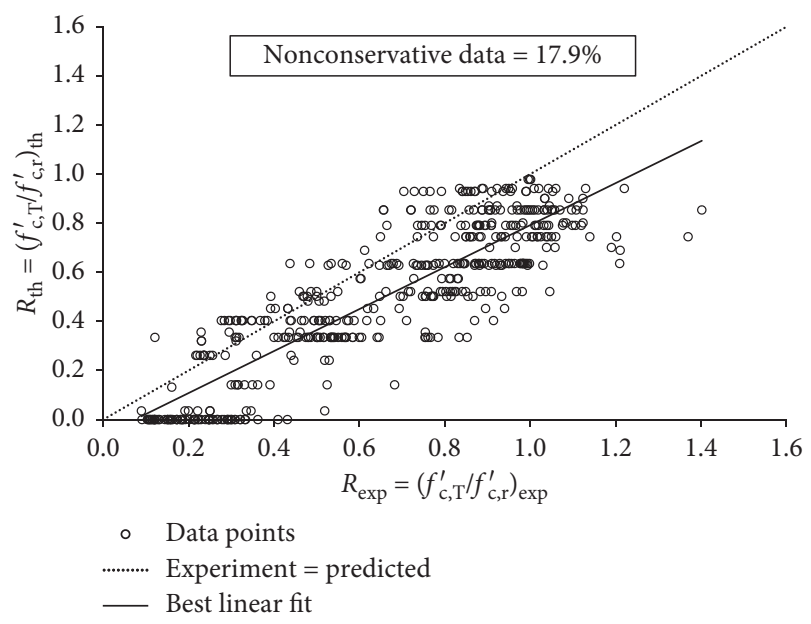

(b)

Figure 10: Continued. 


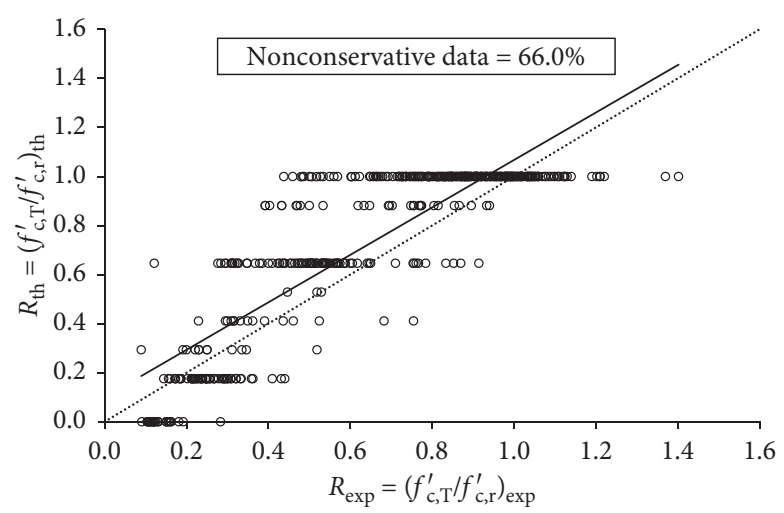

- Data points

.......... Experiment $=$ predicted

- Best linear fit

(c)

Figure 10: Comparison of normalized strength of HSC predicted by the models of different codes with experiment: (a) Eurocode 2: EN 1992-1-2 [4], (b) ACI 216.1-07 [5], and (c) ASCE Manual [6].

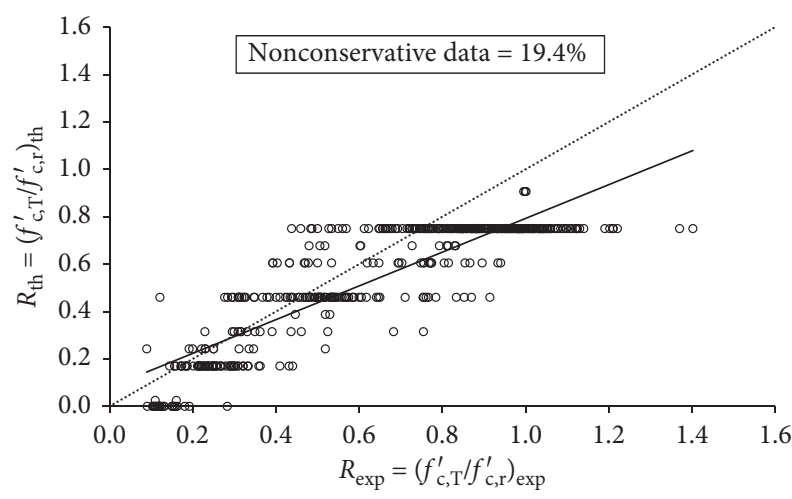

- Data points

......... Experiment $=$ predicted

_ Best linear fit

(a)

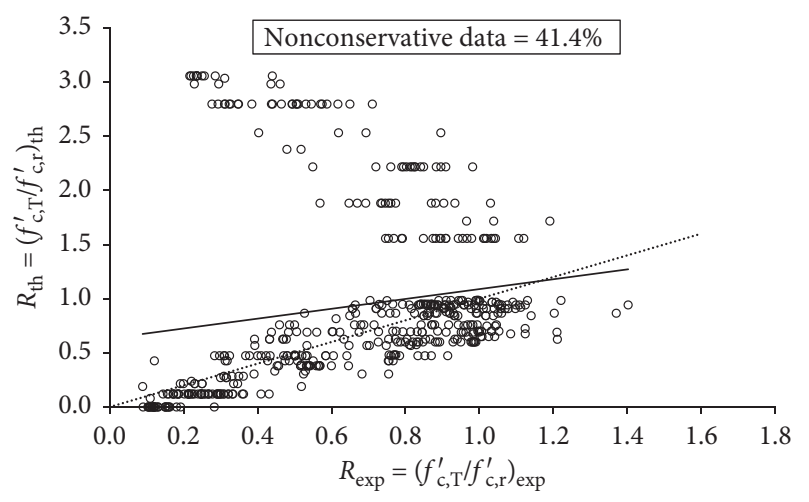

- Data points

…….. Experiment $=$ predicted

_ Best linear fit

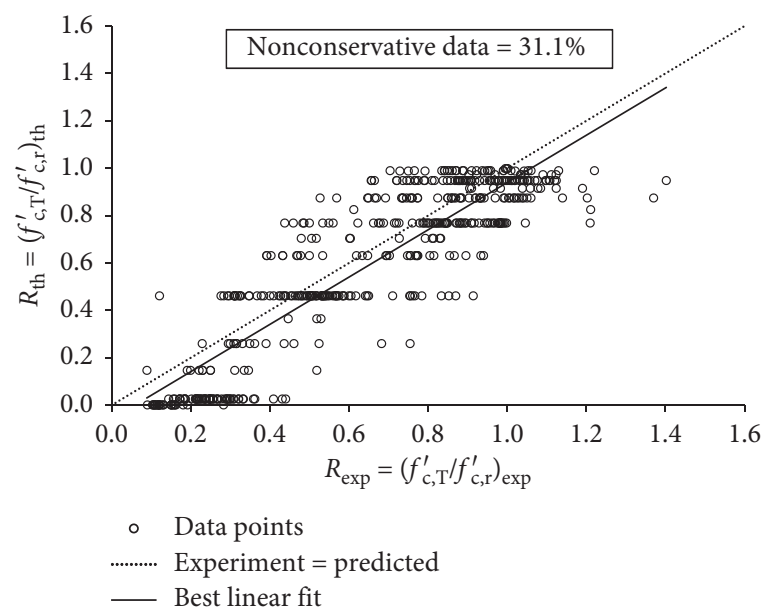

(b)

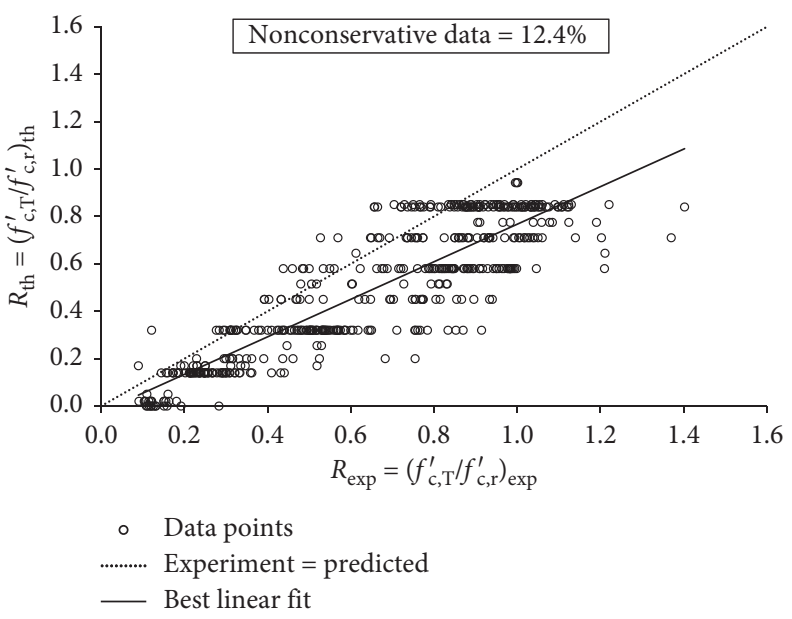

(d)

FIgURe 11: Continued. 


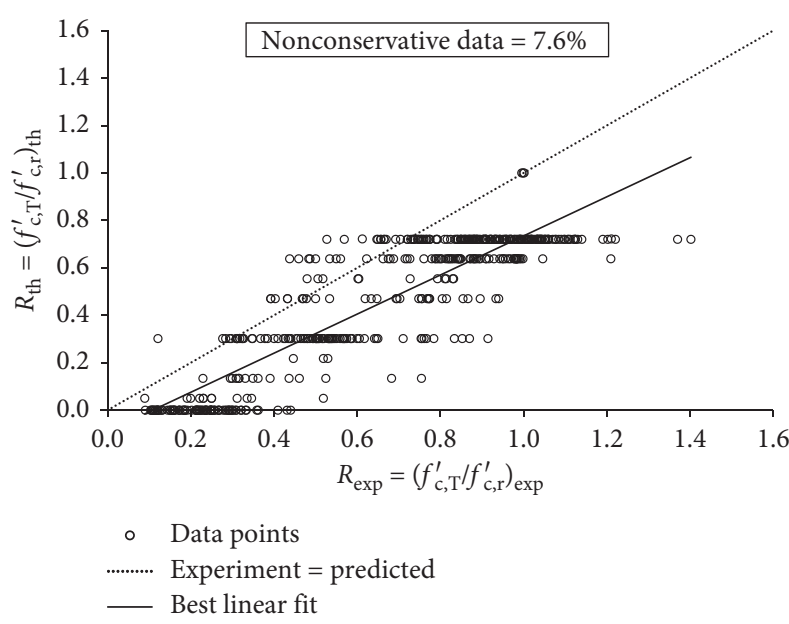

(e)

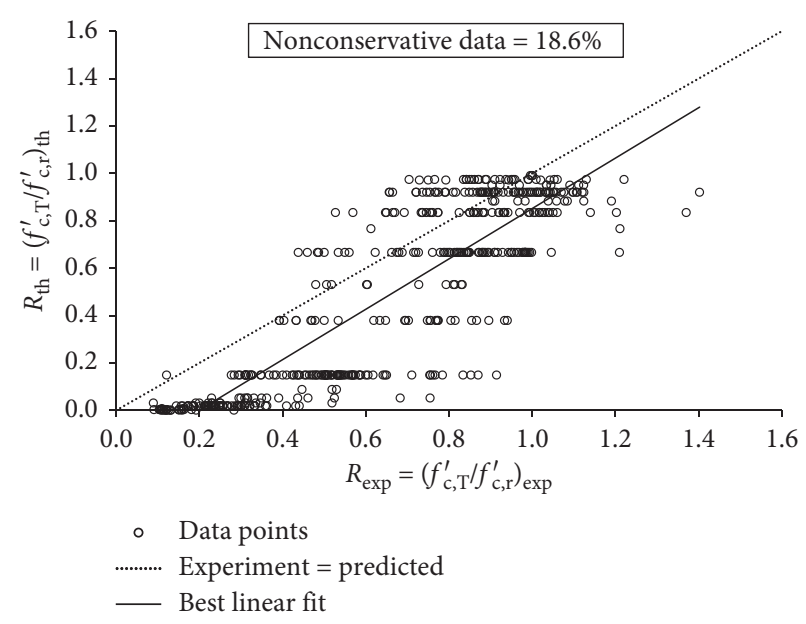

(f)

FIgURE 11: Comparison of normalized strength of HSC predicted by the models of different researchers with experiment: (a) Kodur et al. [29], (b) Nielsen et al. [30], (c) Aslani and Bastami [31], (d) Choe et al. [32], (e) Phan and Carino [33], and (f) Hertz [34].

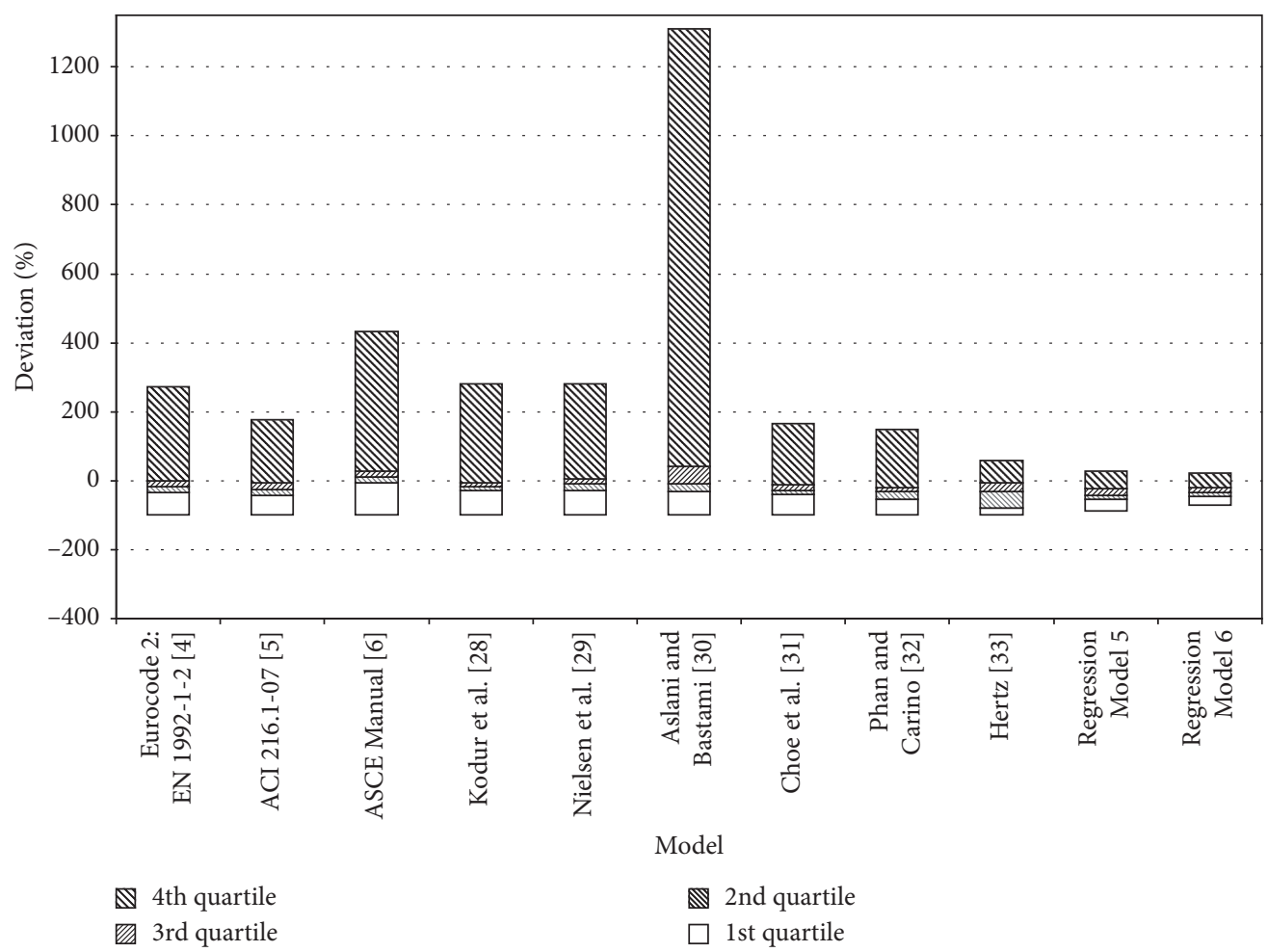

FiguRE 12: Spread of error percentiles for different models.

heating rate. In future, these models may however be reviewed and revised once more data for higher concrete strength and higher heating rate become available.

\section{Conclusions}

The following conclusions can be derived from the current study about the effect of high temperatures on the residual compressive strength of HSC: (i) As expected, the maximum temperature plays by far the major role in controlling residual compressive strength of HSC. The remaining parameters show almost the same level of sensitivity and the effect of these parameters is quite small as compared to the elevated temperature.

(ii) Among the formulae of different codes, ACI 216.107 [5] is better with least nonconservative data, whereas the model of the ASCE Manual [6] is the 
most nonconservative with $66.0 \%$ nonconservative data. Among the researchers' design models, the model of Phan and Carino [33] is the best with the nonconservative data of $7.6 \%$.

(iii) Four regression-based models have been developed for the assessment of the residual compressive strength of HSC. These models propose single formula for whole range of elevated temperature. Two of the models incorporate all identified parameters, whereas the remaining two are a function of the elevated temperature alone. The models show small errors and acceptable correlation coefficients. Based on the models that are a function of the elevated temperature alone, two new design models are proposed. These models are cubic polynomial and power function of temperature, respectively. The proposed design models show low error estimates, and the nonconservative data points do not exceed $6 \%$.

(iv) The proposed models are applicable for highstrength plain concrete produced using OPC and mineral additives such as fly ash or silica fume not exceeding $15 \%$ by weight of the cement. The use of the proposed models should be restricted to HSC of compressive strength up to $100 \mathrm{MPa}$.

(v) Although there is marginal effect of rate of heating on the residual compressive strength of concrete, the future research should focus on higher heating rate corresponding to the fire because the current data are only for the maximum heating rate of $20^{\circ} \mathrm{C} /$ min.

(vi) The test data used in this study were obtained from different test programs by testing HSC specimens of different size and geometry using different heating rates and curing conditions. These differences may lead to inconsistent test results. Therefore, there is a necessity for a standardized test protocol, especially for HSC as the moisture escape path and the rate of pore pressure buildup have a major effect on the behavior of the test specimen. For the sake of comparison of data obtained from different sources, it is highly recommended to create a set of standard test methods. Also, the effects of previous load histories in addition to specimen size and geometry on measured properties should deeply be investigated. Moreover, other material characteristics such as moisture transport properties, pore pressure buildup, and water release during the dehydration process have to be measured as the functions of temperature and heating rate to give input data for theoretical models.

\section{Nomenclature}
$a / b: \quad$ aggregate-to-binder ratio
BP: back propagation
C1 to C7: model parameters

$d$ : diameter of the concrete cylinder or size of the concrete cube in $\mathrm{mm}$

$f_{\mathrm{c}}^{\prime}$ : $\quad$ compressive strength of the standard

$150 \times 300 \mathrm{~mm}$ concrete cylinder

$f_{\mathrm{c}, \mathrm{r}}^{\prime}$ : compressive strength of concrete at room

temperature

$f_{\mathrm{c}, \mathrm{T}}^{\prime}$ : residual compressive strength of concrete after

$f_{\mathrm{cu}}(d)$ : compressive strength of the general cube with size $d$ in $\mathrm{mm}$

$f_{\text {cy }}(h, d)$ : compressive strength of the general cylinder of diameter $d$ in $\mathrm{mm}$ and height $h$ in $\mathrm{mm}$

$h$ : $\quad$ height of the concrete cylinder in $\mathrm{mm}$

$H_{\mathrm{r}}$ : heating rate

$n$ : number of specimens

$n_{1}$ : number of neurons

T: $\quad$ elevated temperature in ${ }^{\circ} \mathrm{C}$

$w / b: \quad$ water-to-binder ratio

$R$ : $\quad$ normalized concrete strength (ratio of residual compressive strength to the compressive strength of concrete at room temperature)

$R_{\text {exp }}$ : measured normalized concrete strength

$R_{\text {th }}$ : $\quad$ predicted normalized concrete strength

$R^{2}$ : $\quad$ coefficient of determination

CC: coefficient of correlation

$\mathrm{CV}$ : coefficient of variation

MAPE: mean absolute percent error

MPE: mean percent error

RMSE: root mean square error

SD: $\quad$ standard deviation.

\section{Data Availability}

The experimental data used to support the findings of this study are available from the author upon request.

\section{Conflicts of Interest}

The author declares no conflicts of interest.

\section{Acknowledgments}

This research was supported by Deanship of Scientific Research Chairs at King Saud University, Saudi Arabia, for Chair of Research and Studies in Strengthening and Rehabilitation of Structures at Civil Engineering Department.

\section{References}

[1] N. Subramanian, "Evaluation and enhancing the punching shear resistance of flat slabs using HSC," Indian Concrete Journal, vol. 79, no. 4, pp. 31-37, 2005.

[2] American Concrete Institute (ACI), Report on High-Strength Concrete, ACI 363R-10, American Concrete Institute, Detroit, MI, USA, 2010.

[3] M. Hamrat, B. Boulekbache, M. Chemrouk, and S. Amziane, "Shear behaviour of RC beams without stirrups made of normal strength and high strength concretes," Advances in Structural Engineering, vol. 13, no. 1, pp. 29-41, 2010.

[4] Comité Européen de Normalisation (CEN), EN 1992-1-2: Eurocode 2: DESIGN of Concrete Structures-Part 1-2: General 
Rules-Structural Fire Design, Comité Européen de Normalisation (CEN), Brussels, Belgium, 2004.

[5] Joint ACI-TMS Committee 216, Code requirements for determining fire resistance of concrete and masonry construction assemblies (ACI-TMS 216.1-07), Joint ACI-TMS Committee 216, Farmington Hills, MI, USA, 2007.

[6] ASCE Committee on Fire Protection, "Structural fire protection: Manual of practice," Manual and Report No. 78, American Society of Civil Engineers, Structural Division, New York, NY, USA, 1992.

[7] H. Elsanadedy, T. Almusallam, Y. Al-Salloum, and R. Iqbal, "Effect of high temperature on structural response of reinforced concrete circular columns strengthened with fiber reinforced polymer composites," Journal of Composite Materials, vol. 51, no. 3, pp. 333-355, 2017.

[8] C. Zhai, L. Chen, Q. Fang, W. Chen, and X. Jiang, "Experimental study of strain rate effects on normal weight concrete after exposure to elevated temperature," Materials and Structures, vol. 50, p. 40, 2017.

[9] T. Drzymała, W. Jackiewicz-Rek, M. Tomaszewski, A. Kuś, J. Gałaj, and R. Šukys, "Effects of high temperature on the properties of high performance concrete (HPC)," Procedia Engineering, vol. 172, pp. 256-263, 2017.

[10] T. Gupta, S. Siddique, R. K. Sharma, and S. Chaudhary, "Effect of elevated temperature and cooling regimes on mechanical and durability properties of concrete containing waste rubber fiber," Construction and Building Materials, vol. 137, pp. 35-45, 2017.

[11] I. Türkmen, A. F. Bingöl, A. Tortum, R. Demirboğa, and R. Gül, "Properties of pumice aggregate concretes at elevated temperatures and comparison with ANN models," Fire and Materials, vol. 41, no. 2, pp. 142-153, 2017.

[12] Y. A. Al-Salloum, T. H. Almusallam, H. M. Elsanadedy, and R. A. Iqbal, "Effect of elevated temperature environments on the residual axial capacity of RC columns strengthened with different techniques," Construction and Building Materials, vol. 115, pp. 345-361, 2016.

[13] J. Huo, B. Jin, Q. Yu, Y. He, and Y. Liu, "Effect of microstructure variation on damage evolution of concrete at high temperatures," ACI Materials Journal, vol. 113, no. 5, pp. $547-558,2016$.

[14] Y. A. Al-Salloum, H. M. Elsanadedy, and A. A. Abadel, "Behavior of FRP-confined concrete after high temperature exposure," Construction and Building Materials, vol. 25, no. 2, pp. 838-850, 2011.

[15] P. Bamonte and P. G. Gambarova, "High-temperature behavior of SCC in compression: comparative study on recent experimental campaigns," Journal of Materials in Civil Engineering, vol. 28, no. 3, article 04015141, 2016.

[16] L. T. Phan and N. J. Carino, "Fire performance of high strength concrete: research needs," in Proceedings of ASCE/ SEI Structures Congress, Philadelphia, PA, USA, May 2000.

[17] M. S. Abrams, Compressive Strength of Concrete at Temperatures to $1600^{\circ} \mathrm{F}$, American Concrete Institute (ACI) SP 25, Temperature and Concrete, Detroit, MI, USA, 1971.

[18] C. Castillo and A. J. Durrani, "Effect of transient high temperature on high-strength concrete," ACI Materials Journal, vol. 87, no. 1, pp. 47-53, 1990.

[19] U. Diederichs, U. M. Jumppanen, and V. Penttala, "Material properties of high strength concrete at elevated temperatures," in Proceedings of the IABSE 13th Congress, Helsinki, Finland, 1988.

[20] U. Diederichs, U. M. Jumppanen, and V. Penttala, "Behavior of high strength concrete at high temperatures," Report No.
92, Helsinki University of Technology, Department of Structural Engineering, Espoo, Finland, 1989.

[21] K. Hertz, "Danish investigations on silica fume concretes at elevated temperatures," in Proceedings of the ACI 1991 Spring Convention, Boston, MA, USA, March 1991.

[22] G. Khoury and S. Algar, "Mechanical behavior of HPC and UHPC concretes at high temperatures in compression and tension," in Proceedings of the ACI International Conference on State-of-the-Art in High Performance Concrete, Chicago, IL, USA, 1999.

[23] H. L. Malhotra, "The effect of temperature on the compressive strength of concrete," Magazine of Concrete Research, vol. 8, no. 22, pp. 85-94, 1956.

[24] L. T. Phan, J. R. Lawson, and F. L. Davis, "Effects of elevated temperature exposure on heating characteristics, spalling, and residual properties of high performance concrete," Materials and Structures, vol. 34, no. 2, pp. 83-91, 2001.

[25] U. Schneider, "Concrete at high temperatures-a general review," Fire Safety Journal, vol. 13, no. 1, pp. 55-68, 1988.

[26] P. J. E. Sullivan and R. Sharshar, "The performance of concrete at elevated temperatures (as measured by the reduction in compressive strength)," Fire Technology, vol. 28, no. 3, pp. 240-250, 1992.

[27] L. T. Phan, Fire Performance of High-Strength Concrete: A Report of the State-of-the-Art, NISTIR 5934, Building and Fire Research Laboratory, National Institute of Standards and Technology, Gaithersburg, MD, USA, 1996.

[28] L. T. Phan and N. J. Carino, "Review of mechanical properties of HSC at elevated temperature," Journal of Materials in Civil Engineering, vol. 10, no. 1, pp. 58-65, 1998.

[29] V. K. R. Kodur, T. C. Wang, and F. P. Cheng, "Predicting the fire resistance behaviour of high strength concrete columns," Cement and Concrete Composites, vol. 26, no. 2, pp. 141-153, 2004.

[30] C. V. Nielsen, C. J. Pearce, and N. Bicanic, "Improved phenomenological modelling of transient thermal strains for concrete at high temperatures," Computers and Concrete, vol. 1, no. 2, pp. 189-209, 2004.

[31] F. Aslani and M. Bastami, "Constitutive relationships for normal- and high-strength concrete at elevated temperatures," ACI Materials Journal, vol. 108, no. 4, pp. 355-364, 2011.

[32] G. Choe, G. Kim, N. Gucunski, and S. Lee, "Evaluation of the mechanical properties of $200 \mathrm{MPa}$ ultra-high-strength concrete at elevated temperatures and residual strength of column," Construction and Building Materials, vol. 86, pp. 159-168, 2015.

[33] L. T. Phan and N. J. Carino, "Code provisions for high strength concrete strength-temperature relationship at elevated temperatures," Materials and Structures, vol. 36, no. 2, pp. 91-98, 2003.

[34] K. D. Hertz, "Concrete strength for fire safety design," Magazine of Concrete Research, vol. 57, no. 8, pp. 445-453, 2005.

[35] L. Liu, Fire performance of high strength concrete materials and structural concrete, Ph.D. thesis, Florida Atlantic University, Boca Raton, FL, USA, 2009.

[36] K. D. Caple, "A pilot study on the effects of temperature on the material properties of prestressed concrete and the use of thermogravimetric analysis in the assessment of heat-affected concrete," M.Sc. thesis, Clemson University, Clemson, SC, USA, 2007.

[37] G.-F. Peng, Evaluation of fire damage to high performance concrete, Ph.D. thesis, The Hong Kong Polytechnic University, Hong Kong, China, 2000.

[38] Y. Xu, Y. L. Wong, C. S. Poon, and M. Anson, "Impact of high temperature on PFA concrete," Cement and Concrete Research, vol. 31, no. 7, pp. 1065-1073, 2001. 
[39] O. Arioz, "Retained properties of concrete exposed to high temperatures: size effect," Fire and Materials, vol. 33, no. 5, pp. 211-222, 2009.

[40] D. J. Martins, J. R. Correia, and J. de Brito, "The effect of high temperature on the residual mechanical performance of concrete made with recycled ceramic coarse aggregates," Fire and Materials, vol. 40, no. 2, pp. 289-304, 2016.

[41] M. Yaqub and C. G. Bailey, "Non-destructive evaluation of residual compressive strength of post-heated reinforced concrete columns," Construction and Building Materials, vol. 120, pp. 482-493, 2016.

[42] L. Biolzi, S. Cattaneo, and G. Rosati, "Evaluating residual properties of thermally damaged concrete," Cement and Concrete Composites, vol. 30, no. 10, pp. 907-916, 2008.

[43] K. S. Al-Jabri, M. B. Waris, and A. H. Al-Saidy, "Effect of aggregate and water to cement ratio on concrete properties at elevated temperature," Fire and Materials, vol. 40, no. 7, pp. 913-925, 2016.

[44] E. A. Kerr, Damage mechanisms and repairability of high strength concrete exposed to elevated temperatures, Ph.D. thesis, University of Notre Dame, Notre Dame, IN, USA, 2007.

[45] M. Bastami, A. Chaboki-Khiabani, M. Baghbadrani, and M. Kordi, "Performance of high strength concretes at elevated temperatures," Scientia Iranica, vol. 18, no. 5, pp. 1028-1036, 2011.

[46] M. Bastami, M. Baghbadrani, and F. Aslani, "Performance of nano-Silica modified high strength concrete at elevated temperatures," Construction and Building Materials, vol. 68, pp. 402-408, 2014.

[47] K. K. Sideris and P. Manita, "Residual mechanical characteristics and spalling resistance of fiber reinforced selfcompacting concretes exposed to elevated temperatures," Construction and Building Materials, vol. 41, pp. 296-302, 2013.

[48] E. Tolentino, F. S. Lameiras, A. M. Gomes, C. A. R. d. Silva, and W. L. Vasconcelos, "Effects of high temperature on the residual performance of Portland cement concretes," Materials Research, vol. 5, no. 3, pp. 301-307, 2002.

[49] R. Felicetti, P. G. Gambarova, M. P. Natali Sora, and G. A. Khoury, "Mechanical behaviour of HPC and UHPC in direct tension at high temperature and after cooling," in Proceedings of the 5th Symposium on Fibre-Reinforced Concrete BEFIB 2000, pp. 749-758, Lyon, France, September 2000.

[50] I. Hager, T. Tracz, J. Śliwiński, and K. Krzemień, “The influence of aggregate type on the physical and mechanical properties of high-performance concrete subjected to high temperature," Fire and Materials, vol. 40, no. 5, pp. 668-682, 2016.

[51] J. Lee, K. Choi, and K. Hong, "The effect of high temperature on color and residual compressive strength of concrete," in Proceedings of Fracture Mechanics of Concrete and Concrete Structures (FraMCoS-7), pp. 1772-1775, Jeju, South Korea, May 2010.

[52] A. H. Ahmad and O. M. Abdulkareem, "Effect of high temperature on mechanical properties of concrete containing admixtures," Al-Rafidain Engineering Journal, Iraq, vol. 18, no. 4, pp. 43-54, 2010.

[53] S. H. Chowdhury, "Effect of elevated temperature on mechanical properties of high strength concrete," in Proceedings of the 23rd Australasian conference on the mechanics of structures and materials (ACMSM23), S. T. Smith, Ed., pp. 1077-1082pp. 1077-, Byron Bay, Australia, December 2014.
[54] C. B. K. Rao and R. Kumar, "A study on behaviour of normal strength concrete and high strength concrete subjected to elevated temperatures," International Journal of Civil, Environmental, Structural, Construction and Architectural Engineering, vol. 9, no. 3, pp. 283-287, 2015.

[55] A. Lau, Effect of high temperatures on normal strength concrete and high performance concrete containing steel fibers, Ph.D. thesis, The Hong Kong Polytechnic University, Hong Kong, China, 2003.

[56] J. A. Purkiss, "Steel fibre reinforced concrete at elevated temperatures," International Journal of Cement Composites and Lightweight Concrete, vol. 6, no. 3, pp. 179-184, 1984.

[57] I. Netinger, M. J. Rukavina, and A. Mladenovič, "Improvement of post-fire properties of concrete with steel slag aggregate," Procedia Engineering, vol. 62, pp. 745-753, 2013.

[58] B. Toumi, M. Resheidat, Z. Guemmadi, and H. Chabil, "Coupled effect of high temperature and heating time on the residual strength of normal and high-strength concretes," Jordan Journal of Civil Engineering, vol. 3, no. 4, pp. 322-330, 2009.

[59] M. Uysal and H. Tanyildizi, "Estimation of compressive strength of self compacting concrete containing polypropylene fiber and mineral additives exposed to high temperature using artificial neural network," Construction and Building Materials, vol. 27, no. 1, pp. 404-414, 2012.

[60] S. Hachemi, A. Ounis, and S. Chabi, "Evaluating residual mechanical and physical properties of concrete at elevated temperatures," International Journal of Civil, Environmental, Structural, Construction and Architectural Engineering, vol. 8, no. 2, pp. 176-181, 2014.

[61] A. Noumowe and C. Galle, "Study of high strength concretes at raised temperature up to $200{ }^{\circ} \mathrm{C}$ : thermal gradient and mechanical behavior," in Proceedings of the SMiRT 16 Conference, pp. 1-8, International Association for Structural Mechanics in Reactor Technology (IASMiRT), Washington DC, USA, August 2001.

[62] Y. N. Chan, G. F. Peng, and M. Anson, "Residual strength and pore structure of high-strength concrete and normal strength concrete after exposure to high temperatures," Cement and Concrete Composites, vol. 21, no. 1, pp. 23-27, 1999.

[63] B. Demirel and O. Keleştemur, "Effect of elevated temperature on the mechanical properties of concrete produced with finely ground pumice and silica fume," Fire Safety Journal, vol. 45, no. 6-8, pp. 385-391, 2010.

[64] N. Anagnostopoulos, K. K. Sideris, and A. Georgiadis, "Mechanical characteristics of self-compacting concretes with different filler materials, exposed to elevated temperatures," Materials and Structures, vol. 42, no. 10, pp. 1393-1405, 2009.

[65] O. Arioz, "Effects of elevated temperatures on properties of concrete," Fire Safety Journal, vol. 42, no. 8, pp. 516-522, 2007.

[66] A. Behnood and M. Ghandehari, "Comparison of compressive and splitting tensile strength of high-strength concrete with and without polypropylene fibers heated to high temperatures," Fire Safety Journal, vol. 44, no. 8, pp. 1015-1022, 2009.

[67] Z. Bin Johari, "Mechanical properties of high strength concrete at high temperature loading," M.Sc. thesis, Universiti Tecknologi Malaysia, Johor Bahru, Malaysia, 2005.

[68] M. S. Cülfik and T. Özturan, "Mechanical properties of normal and high strength concretes subjected to high temperatures and using image analysis to detect bond deteriorations," Construction and Building Materials, vol. 24, no. 8, pp. 1486-1493, 2010. 
[69] Y. Esen, "The effect of cure conditions and temperature changes on the compressive strength of normal and fly ash added concretes," International Journal of the Physical Sciences, vol. 5, no. 17, pp. 2598-2604, 2010.

[70] D. Campbellallen, E. Low, and H. Roper, "An investigation on the effect of elevated temperatures on concrete for reactor vessels放," Nuclear Engineering and Design, vol. 2, no. 4, pp. 382-388, 1965.

[71] K. Hertz, Heat-Induced Explosion of Dense Concrete, Report No. 166, Institute of Building Design, Technical University of Denmark, Lyngby, Denmark, 1984.

[72] M. S. Khan and H. Abbas, "Performance of concrete subjected to elevated temperature," European Journal of Environmental and Civil Engineering, vol. 20, no. 5, pp. 532-543, 2016.

[73] M. Khandaker and A. Hossain, "High strength blended cement concrete incorporating volcanic ash: performance at high temperatures," Cement and Concrete Composites, vol. 28, no. 6, pp. 535-545, 2006.

[74] A. Noumowe, "Mechanical properties and microstructure of high strength concrete containing polypropylene fibres exposed to temperatures up to $200^{\circ} \mathrm{C}$," Cement and Concrete Research, vol. 35, no. 11, pp. 2192-2198, 2005.

[75] A. Noumowé, H. Carré, A. Daoud, and H. Toutanji, "Highstrength self-compacting concrete exposed to fire test," Journal of Materials in Civil Engineering, vol. 18, no. 6, pp. 754-758, 2006.

[76] C. S. Poon, Z. H. Shui, and L. Lam, "Compressive behavior of fiber reinforced high-performance concrete subjected to elevated temperatures," Cement and Concrete Research, vol. 34, no. 12, pp. 2215-2222, 2004.

[77] A. Savva, P. Manita, and K. K. Sideris, "Influence of elevated temperatures on the mechanical properties of blended cement concretes prepared with limestone and siliceous aggregates," Cement and Concrete Composites, vol. 27, no. 2, pp. 239-248, 2005.

[78] F. U. A. Shaikh and V. Vimonsatit, "Effect of cooling methods on residual compressive strength and cracking behavior of fly ash concretes exposed at elevated temperatures," Fire and Materials, vol. 40, no. 2, pp. 335-350, 2016.

[79] J. Xiao and H. Falkner, "On residual strength of highperformance concrete with and without polypropylene fibres at elevated temperatures," Fire Safety Journal, vol. 41, no. 2, pp. 115-121, 2006.

[80] C. J. Zega and A. A. Di Maio, "Recycled concrete made with different natural coarse aggregates exposed to high temperature," Construction and Building Materials, vol. 23, no. 5, pp. 2047-2052, 2009.

[81] J. Geng, Q. Sun, W. Zhang, and C. Lü, "Effect of high temperature on mechanical and acoustic emission properties of calcareous-aggregate concrete," Applied Thermal Engineering, vol. 106, pp. 1200-1208, 2016.

[82] T. Morita, H. Saito, and H. Kumagai, "Residual mechanical properties of high strength concrete members exposed to high temperature-Part 1. Test on material properties," in Proceedings of the Summaries of Technical Papers of Annual Meeting, Architectural Institute of Japan, Niigata, Japan, August 1992.

[83] Z. Xing, A.-L. Beaucour, R. Hebert, A. Noumowe, and B. Ledesert, "Influence of the nature of aggregates on the behaviour of concrete subjected to elevated temperature," Cement and Concrete Research, vol. 41, no. 4, pp. 392-402, 2011.

[84] H.-S. Shang and T.-H. Yi, "Behavior of HPC with fly ash after elevated temperature," Advances in Materials Science and Engineering, vol. 2013, Article ID 478421, 7 pages, 2013.
[85] S.-T. Yi, E.-I. Yang, and J.-C. Choi, "Effect of specimen sizes, specimen shapes, and placement directions on compressive strength of concrete," Nuclear Engineering and Design, vol. 236, no. 2, pp. 115-127, 2006.

[86] ULC, CAN/ULC-S101-M04: Standard Methods of Fire Endurance Tests of Building Construction and Materials, Underwriters' Laboratories of Canada, Scarborough, Canada, 2004.

[87] ASTM, ASTM E119-01: Standard Methods of Fire Test of Building Construction and Materials, American Society for Testing and Materials, West Conshohocken, PA, USA, 2001.

[88] ISO, Fire-Resistance Tests-Elements of Building ConstructionPart 1: General Requirements, ISO 834-1:1999, International Organization for Standardization, Geneva, Switzerland, 1999.

[89] A. M. Knaack, Y. C. Kurama, and D. J. Kirkner, "Compressive strength relationships for concrete under elevated temperatures," ACI Materials Journal, vol. 107, no. 2, pp. 164-175, 2010.

[90] P. Bamonte and P. G. Gambarova, "High-temperature behavior of SCC in compression: comparative study on recent experimental campaigns," Journal of Materials in Civil Engineering, vol. 28, no. 3, article 04015141, 2016.

[91] M. di Prisco, R. Felicetti, P. G. Gambarova, and C. Failla, "On the fire behavior of SFRC and SFRC structures in tension and bending," in Proceedings of the 4th International Workshop on High-Performance Fiber-Reinforced Cement Composites HPFRCC-4, A. E. Naaman and H. W. Reinhardt, Eds., pp. 205-220, RILEM, Ann Arbor, MI, USA, June 2003.

[92] H. Abbas, S. H. Alsayed, T. H. Almusallam, and Y. A. AlSalloum, "Characterization of hole-diameter in thin metallic plates perforated by spherical projectiles using genetic algorithms," Archive of Applied Mechanics, vol. 81, no. 7, pp. 907-924, 2011.

[93] H. M. Elsanadedy, Y. A. Al-Salloum, H. Abbas, and S. H. Alsayed, "Prediction of strength parameters of FRPconfined concrete," Composites Part B: Engineering, vol. 43, no. 2, pp. 228-239, 2012.

[94] H. M. Elsanadedy, H. Abbas, Y. A. Al-Salloum, and T. H. Almusallam, "Prediction of intermediate crack debonding strain of externally bonded FRP laminates in RC beams and one-way slabs," Journal of Composites for Construction, vol. 18, no. 5, article 04014008, 2014.

[95] A. A. Shah, S. H. Alsayed, H. Abbas, Y. A. Al-Salloum, and T. H. Almusallam, "Predicting residual strength of non-linear ultrasonically evaluated damaged concrete using artificial neural network," Construction and Building Materials, vol. 29, pp. 42-50, 2012.

[96] H. M. Elsanadedy, H. Abbas, Y. A. Al-Salloum, and T. H. Almusallam, "Shear strength prediction of HSC slender beams without web reinforcement," Materials and Structures, vol. 49, no. 9, pp. 3749-3772, 2016.

[97] D.-K. Bui, T. Nguyen, J.-S. Chou, H. Nguyen-Xuan, and T. D. Ngo, "A modified firefly algorithm-artificial neural network expert system for predicting compressive and tensile strength of high-performance concrete," Construction and Building Materials, vol. 180, pp. 320-333, 2018.

[98] T. Nguyen, A. Kashani, T. Ngo, and S. Bordas, "Deep neural network with high-order neuron for the prediction of foamed concrete strength," Computer-Aided Civil and Infrastructure Engineering, vol. 34, no. 4, pp. 316-332, 2018.

[99] H. Abbas, Y. A. Al-Salloum, H. M. Elsanadedy, and T. H. Almusallam, "ANN models for prediction of residual strength of HSC after exposure to elevated temperature," Fire Safety Journal, vol. 106, pp. 13-28, 2019. 


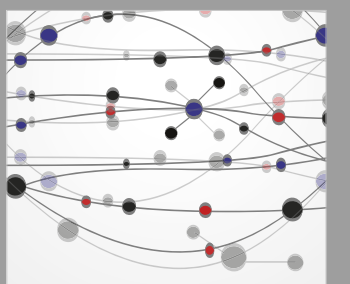

The Scientific World Journal
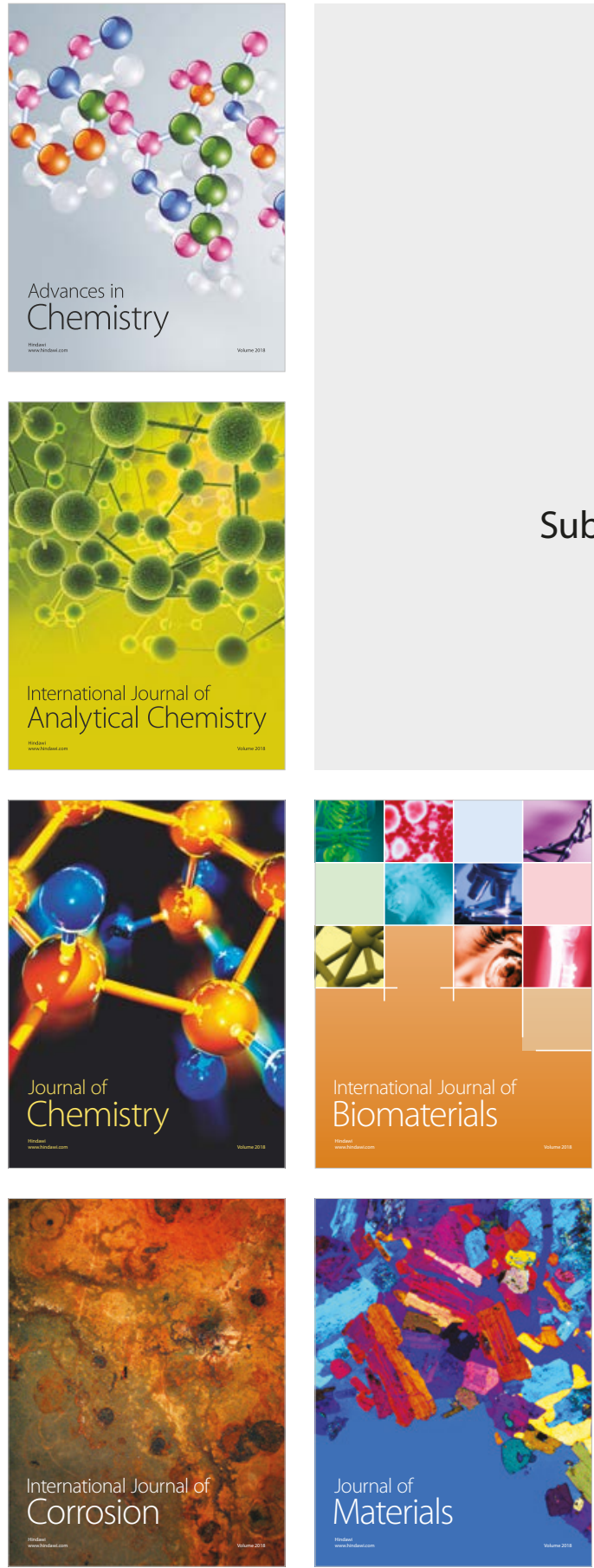

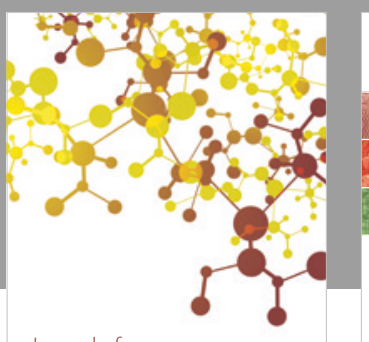

Journal of

Applied Chemistry
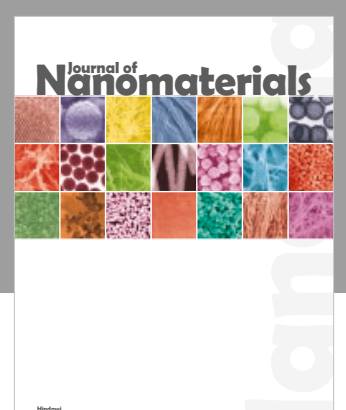

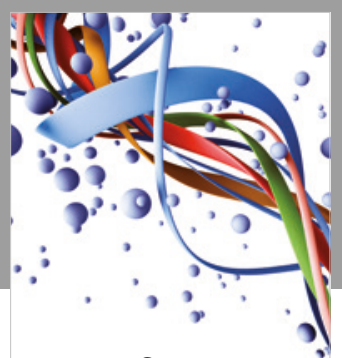

Scientifica

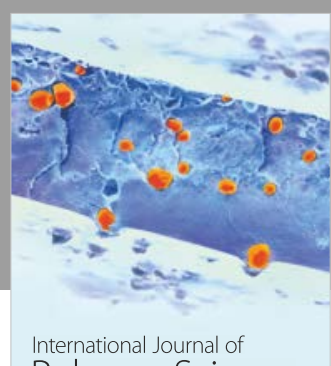

Polymer Science

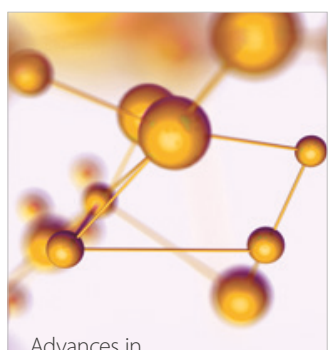

Physical Chemistry
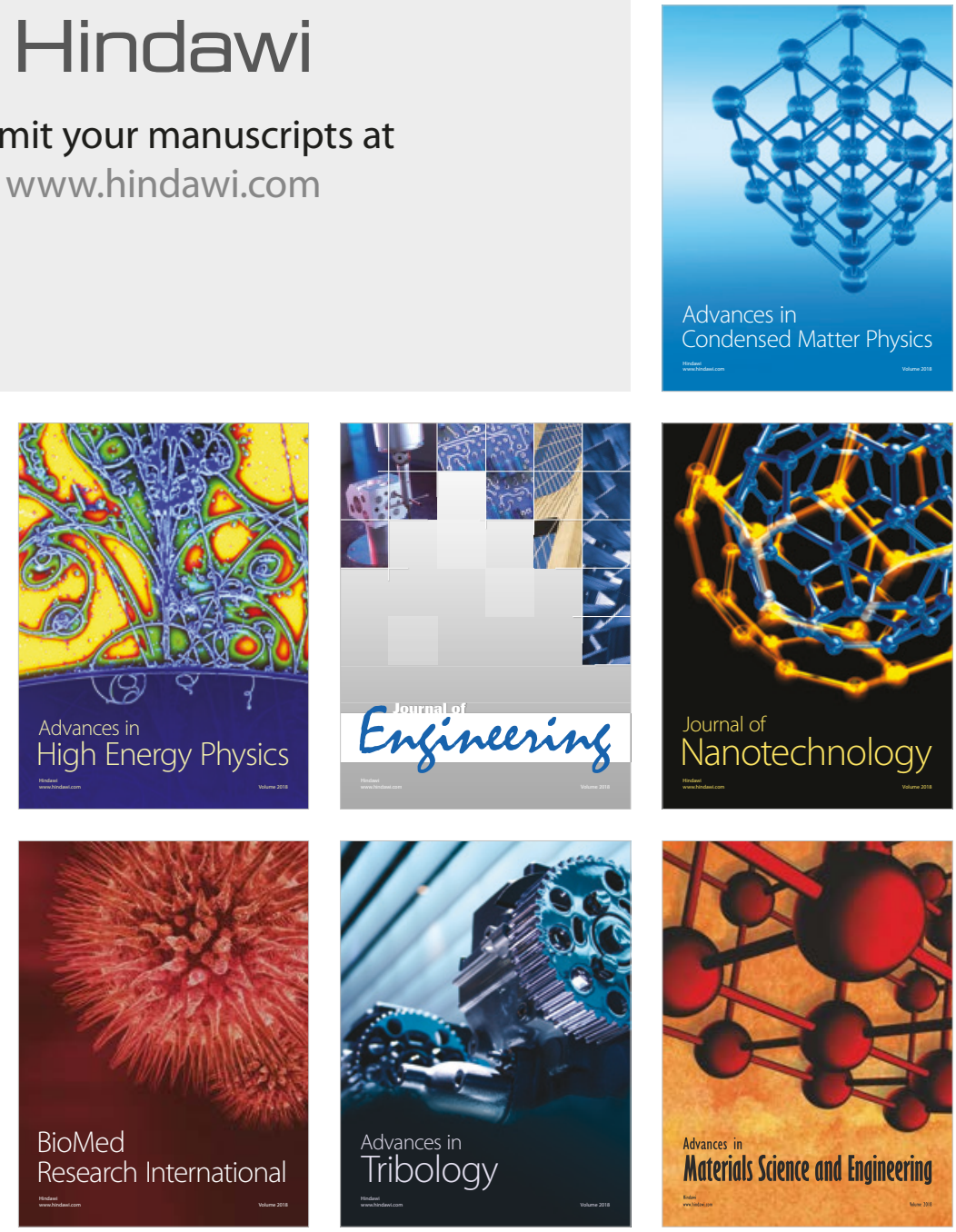